\title{
From Endogenous to Synthetic microRNA-Mediated Regulatory Circuits: An Overview
}

\author{
Elsi Ferro ${ }^{1,2,+}$, Chiara Enrico Bena ${ }^{1,2,+(1)}$, Silvia Grigolon $3, *$ (1) and Carla Bosia $1,4, *$ (D) \\ 1 IIGM-Italian Institute for Genomic Medicine, c/o IRCCS, 10060 Candiolo (Torino), Italy \\ 2 Candiolo Cancer Institute, FPO-IRCCS, 10060 Candiolo (Torino), Italy \\ 3 The Francis Crick Institute, 1 Midland Road, London NW1 1AT, UK \\ 4 Department of Applied Science and Technology, Politecnico di Torino, Corso Duca degli Abruzzi 24, \\ 10129 Torino, Italy \\ * Correspondence: silvia.grigolon@crick.ac.uk (S.G.); carla.bosia@polito.it (C.B.) \\ + These authors contributed equally to this work.
}

Received: 31 October 2019; Accepted: 25 November 2019; Published: 29 November 2019

\begin{abstract}
MicroRNAs are short non-coding RNAs that are evolutionarily conserved and are pivotal post-transcriptional mediators of gene regulation. Together with transcription factors and epigenetic regulators, they form a highly interconnected network whose building blocks can be classified depending on the number of molecular species involved and the type of interactions amongst them. Depending on their topology, these molecular circuits may carry out specific functions that years of studies have related to the processing of gene expression noise. In this review, we first present the different over-represented network motifs involving microRNAs and their specific role in implementing relevant biological functions, reviewing both theoretical and experimental studies. We then illustrate the recent advances in synthetic biology, such as the construction of artificially synthesised circuits, which provide a controlled tool to test experimentally the possible microRNA regulatory tasks and constitute a starting point for clinical applications.
\end{abstract}

Keywords: microRNA; network motifs; synthetic circuits

\section{Introduction}

Life as we see it is the result of the complex regulation of organisms' gene expression, required to fulfil vital biological tasks. This complexity is well reflected by the intricate network of interactions between the thousands of genes constituting genomes. Specifically, these interactions are triggered by the action of transcription factors (TFs), which are the regulatory molecules carrying out the primary step of either enhancing or inhibiting their target gene's transcription. The sum of all transcriptional regulatory relationships throughout an organism's genome constitutes its transcription network.

Originally, transcription networks were found to be built up of recurring patterns, called network motifs [1]. Identical motifs have been observed in different organisms ranging from bacteria to humans, indicating that they constitute the basic subcomponents of transcription networks [2]. The most acknowledged small scale motifs involve single or multiple target genes and one or more TFs as master regulators. Depending on its topology, each type of circuit can carry out defined information processing functions that allow achieving a specific biological task [3]. For example, positive self-loops slow down dynamical responses and increase variability, whereas negative auto-regulation is well known for accelerating responses and decreasing noise [4,5]. Coherent feedforward loops can display response persistence, while incoherent feedforward loops show a hallmark pulse-like outcome and speed up response. Single input modules, made up of a single TF regulating multiple genes, can generate temporal expression programmes [2]. 
The same motifs were later found in mixed regulatory networks, that is in networks that are not necessarily limited to transcriptional interactions [6,7], and multiple studies have highlighted the role of microRNAs (miRNAs) as pivotal players in these circuits [8].

MiRNAs are evolutionarily conserved $\sim 22 \mathrm{nt}$ long non-coding RNA molecules that act as post-transcriptional gene regulators. Such regulation is achieved through Watson-Crick base pairing with the target mRNAs, mainly at their $5^{\prime}$ terminus or inside their $3^{\prime}$-UTR region [9]. The strength of binding, that is the degree of miRNA-mRNA complementarity, determines whether the target mRNA will be subject to translational repression or mRNA degradation: partial complementarity inhibits translation, while near-perfect matching results in its degradation $[10,11]$. Although a large number of miRNA genes are dispersed over the genome in intergenic regions, more than half of miRNAs reside in introns of their host genes [12], and bioinformatic analyses suggest that they are usually oriented on the same DNA strand of the host [13]. Thus, miRNA biogenesis occurs from both independently transcribed and intron-embedded primary miRNAs [14].

The minimum requirement for miRNA-mRNA interaction is a binding sequence of six consecutive nucleotides, often called "miRNA seed" [15]. Such a soft constraint allows an miRNA molecule to bind potentially hundreds of different genes [10]. Indeed, miRNAs typically act in a combinatorial fashion: a single gene is often targeted by many different miRNAs, and a single miRNA regulates multiple genes [16]. So far, over 2500 different mature miRNAs have been observed in humans [11], and an increasing number of regulatory interactions involving miRNAs is currently being uncovered both by theoretical prediction methods and experimental validation [17].

The way miRNAs interact with their targets is titrative [18]. From a theoretical point of view, titration mechanisms are characterised by a threshold effect close to the equimolarity of the different interacting species, hypersensitivity of the system around the threshold and cross-talk among targets [19-21]. The latter characteristic, also identified as a competing endogenous RNA (ceRNA) effect, marks indirect interactions among targets in competition for a common pool of miRNAs [22,23]. These targets may include protein coding messenger RNAs and non-coding RNAs such as long non-coding RNAs [24,25], pseudogenes [26,27] and circular RNAs [28] that act as natural miRNA sponges, thus co-regulating each other in an miRNA mediated fashion. Within this context, the notion of trios comprised of one miRNA, one non-coding RNA sponging the miRNA, and one target messenger RNA has received increasing attention.

MiRNAs regulate fundamental biological processes, such as embryonic development and synaptic plasticity [6], and play pivotal roles in disease related contexts including diabetes, viral infection [29] and tumourigenesis $[30,31]$. Along with the interaction of miRNAs with TFs in the most diverse biological contexts, their relationship with epigenetics is being increasingly uncovered [32]. However, it is still partially unclear why miRNAs are so pervasive and conserved. Although there are examples of in vivo transgenic models either overexpressing or silencing specific miRNAs that produce a phenotype [33-36], single miRNAs generally exert weak repressive action on their target genes and rarely show phenotypic outcomes [37].

Furthermore, the results obtained by analysing multi-omics data obtained by over- or down-expressing a single miRNA in a given cell-line are not always in line with this idea. For instance, M'baya-Moutoula and collaborators studied the effects of both enhancement and inhibition of a metabolic disease related miRNA, $m i R-223$, in a monocyte macrophage cell-line [38]. After the identification of a great number of candidate regulators and targets of $m i R-223$, the most significantly affected ones were uncovered to be key metabolites. Thus, miR-223 alone seems to be able to clearly alter cells' metabolic profiles, possibly impacting on apoptosis and proliferation. Furthermore, $m i R-34 a$, a notable tumour suppressor, has been identified as a hub in miRNA involving regulatory networks [39]. Specifically, Hart and colleagues [39] investigated its influence on genes regulating the immune system in three different T-cell-lines. Fourteen miR-34a targets out of 193 candidates were experimentally confirmed to affect T-cell function. Hence, the authors suggested a crucial role of miR-34a in T-cell 
regulation that could be exploited to modulate immune response in cancer related contexts for therapeutic purposes.

The identification of therapeutic miRNA targets has been lately addressed by Calsina and colleagues [40] with a multi-omics data analysis in the context of rare neuroendocrine tumours [40]. Prognostic miRNA markers for two specific types of tumour were searched for by integrating transcriptome, proteome and miRNome data and by validating predictions in vitro. Among the group of miRNAs identified as a signature of metastasis and progression, a combination of two of them displayed the strongest correlation with metastatic risk. Specifically, the miR-21-3p/miR-183-5p axis by itself appears to have the power to critically affect tumour development. Genes altered in the same cancer types were also linked to overexpression of the 182/96/183 miRNA cluster and to knockdown of the DLK1-MEG3 miRNA cluster [41].

In essence, even though the single miRNA-target interaction seldom displays phenotypic outcomes, a number of works suggest that single miRNAs or families involved in a broader interactome, where their alteration might give rise to cascade-like consequences, can concretely affect cell state and function.

The emerging idea is that miRNA mediated regulation could serve to manage the impact of noise in gene expression [42]. A number of studies have addressed the relationship between miRNA and noise, and the results suggested that miRNAs could provide precision to protein expression by buffering noise when needed $[37,43]$ or either exploit stochasticity in biological contexts that take advantage of gene expression variability, such as differentiation processes [44,45].

In this review, we first focus on the roles of microRNAs in network motifs, which will be discriminated by their different topologies. We will then address artificially synthesised circuits, which provide additional insight into the possible regulatory tasks that miRNAs can potentially accomplish and ways of taking advantage of miRNAs' functionalities in artificial systems.

\section{MicroRNAs in Network Motifs}

The interplay between miRNAs and TFs in a mixed regulatory circuit, where transcriptional, post-transcriptional and epigenomic regulatory interactions are joined together, has been proposed as a guiding structure for the achievement of genetic tasks. The influence of TFs and epigenetic regulators on miRNAs and vice versa was initially addressed computationally and also recently confirmed experimentally, mainly using RNA sequencing (RNA-seq) and CLIP (crosslinking followed by immunoprecipitation) sequencing (CLIP-seq). Analyses of data from the Encyclopedia of DNA Elements (ENCODE) showed that miRNA mediated circuits are found in real networks significantly more often than expected by chance, as reviewed in $[17,46]$.

Along with the identification and experimental validation of over-represented network motifs, which has been possible thanks to the interplay between bioinformatics and computational methodologies, as well as high throughput and sophisticated modern technologies, mathematical modelling has been shown to be a powerful tool in the understanding of motif functionality. In the models formulated over the past years, the miRNA mediated gene expression regulation is studied as a dynamical system. More broadly, such modelling has also been used for investigating cell and tissue functions at both spatial and temporal resolution and used as a prediction tool for drug and therapy development [11]. As clearly discussed in [11], the key ingredients of the modelling of such gene regulatory networks are the molecular species that compose the network and their interactions. Gene expression is currently well understood to be a stochastic process [47]. Given the probabilistic nature of chemical reactions and the small number of molecules involved, fluctuations in the abundance of such molecules are relevant. Thus, through stochastic modelling, several works deeply investigated the properties and biological advantages of such networks in the presence of different sources of noise $[45,48,49]$.

Specifically, a few miRNA mediated circuits are recurring network motifs in mixed regulatory circuits (Figures 1 and 2). Tsang and colleagues [6] developed a computational method for analysing 
gene expression data, and the results indicated that two classes of circuits are enriched in the human genome, namely miRNA mediated feedback and feedforward loops (FFLs). More precisely, miRNAs appear to be often involved in negative feedback circuits and in both coherent and incoherent FFLs. Moreover, intronic miRNA mediated self-loops (iMSLs), where an miRNA is encoded within an intron of one of its targets, are also significantly represented in the human regulatory network [13], suggesting their potential to implement biologically relevant tasks. In this section, we will discuss the main properties of the most common miRNA mediated motifs, reviewing both theoretical and experimental studies. These will include miRNA mediated feedback and feed-forward loops, with double negative feedback loops and intronic miRNA mediated self-loops as peculiar cases.

\subsection{MicroRNA Mediated Feedback Loops}

Feedback loops (FLs) are among the over-represented miRNA motifs. An FL is a circuit whose topology is such that the output of the network influences the state of the input. This way, the output literally "feeds back" on the input. Positive and negative feedback regulation is intuitively useful. For instance, a TF can limit its own activity by activating a repressor, whereas a double negative feedback loop can function as a switch between cell states by producing a binary output [42].

As mentioned, an increasing number of TF-miRNA circuits have been identified as FLs [11]. In these circuits, as shown in Figure 1a, a TF either enhances or suppresses the expression of an miRNA, which in turn post-transcriptionally suppresses the TF [50]. It has been shown that this kind of circuit can implement a variety of biological functions, ranging from the conversion of a transient upstream signal in a long-lasting cellular response [6] to the achievement of bistable gene expression and buffering of noise, be it due to fluctuating transcription, translation and decay processes (intrinsic noise) or to external (e.g., environmental) factors (extrinsic noise) [11].

The first mentioned feature, that is the response persistence, has been observed for instance in human breast cells, where an FL involves the let-7 miRNA [51]. The activation of the tyrosine-kinase Src triggers NF- $\kappa \mathrm{B}$, a TF known for inducing inflammatory response [52]. NF- $\kappa \mathrm{B}$ in turn activates LIN28, while LIN28 inhibits let-7 [52]. Since the latter represses IL-6, the consequence of a Src activation is a reduced suppression of IL- 6 by the miRNA [52]. IL- 6 completes the loop by activating NF- $\kappa$ B; the result is an FL that maintains the cell state triggered by Src activation also in the absence of the initial input [16]. However, the interaction between let-7 and LIN28 appears to be more complex: it is proposed that they in turn form a double negative FL [53]; see Figure 1b. Recently, the let-7/LIN28 switch has been related to non-small cell lung cancer as well: Yin and colleagues showed that dysregulation of this circuit, which is induced by irradiation or chemotherapeutic drugs, can lead to radio- and chemo-resistance [54].

As a consequence of their importance in determining phenotypic outcomes, miRNAs appear to be largely involved in cancer related feedback motifs [55]. A well known example involves the E2F transcription factor, which is notoriously implicated in the regulation of cancer associated phenotypes. E2F can be regulated by multiple miRNAs belonging to the miR-17-92 cluster [56]. The cluster is induced by E2F, while some miRNAs of the cluster inhibit E2F post-transcriptionally, thus forming an FL (see Figure 1d). Lai and co-workers [11] showed by ODE modelling and stochastic simulation that the miRNA cluster can either function as an oncogene or tumour suppressor depending on the values of two key parameters: the growth factor signalling intensity and the inhibition of E2F translation by the miRNA cluster. Moreover, they showed that introducing noise into external signalling or into E2F expression, the miRNA cluster functions as a noise buffer, thus conferring robustness to the network. However, there exist several other regulatory loops involving miRNAs in the E2F family interactome [57]; thus, the E2F regulation network will require further modelling efforts.

A newly published work by Zargar et al. [58] linked miR-155 to Pdcd4 (programmed cell death 4) and AP-1 in a net positive feedback loop whose different outcomes can lead either to tongue cancer progression (miR-155 overexpression) or to apoptosis and regression of tumour size (miR-155 knockdown); see Figure 1f. 


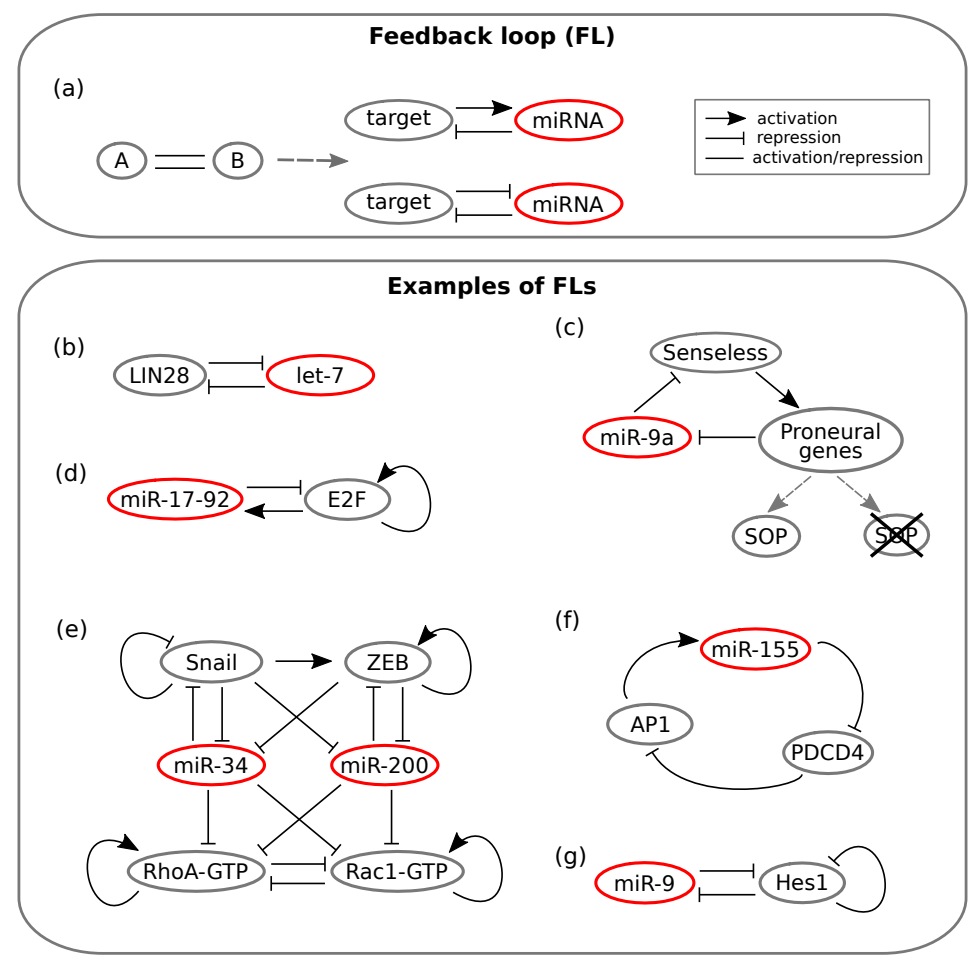

Figure 1. Schemes of feedback loops (FLs). Lines ending with an arrow indicate activation, whereas $\mathrm{T}$ ending lines indicate repression. Simple straight lines indicate that the interaction can either be activatory or repressive. (a) On the left, the general FL scheme is represented. On the right, the two possible configurations of a minimal miRNA mediated FL are reported. Adapted from [2]. (b-f) Experimental examples of miRNA mediated FLs. (b) Toggle switch between LIN28 and the let-7 miRNA involved both in inflammation and non-small cell lung cancer. Adapted from [59]. (c) Double negative FL between Senseless and miR-9a that regulates Drosophila sense organ specification. Adapted from [42]. (d) Cancer associated positive FL between the miR-17-92 family and E2F. E2F self-activation is also represented. Adapted from [60]. (e) Regulatory relationships that control transitions between epithelial, mesenchymal and amoeboid phenotypes. The network is composed of multiple feedback-like interactions. Adapted from [61]. (f) Positive feedback loop between miR-155 and AP1 involved in tongue cancer progression. Adapted from [62]. (g) Toggle switch between miR-9 and Hes1 that controls timing of neuron differentiation. Adapted from [63].

Along with their protein expression fine tuning and noise buffering properties, it appears that miRNA mediated FLs can generate oscillatory gene expression under some conditions [64]. In this type of regulatory pattern, the FL components are alternatively repressed or activated over time [11]. For instance, if a TF slowly activates the transcription of an miRNA, whereas the miRNA rapidly inhibits the TF by repressing its translation or enhancing its degradation, sustained oscillations emerge [11]. Xue and coworkers [65] examined another loop involving NF- $\kappa B$ : the indirect negative FL between $m i R-21$ and NF- $\kappa$ B. This circuit was shown to produce oscillations in NF- $\kappa$ B levels. On the other hand, the related negative FL formed by miR-146ab and IL- 6 contributed by dampening the oscillations [11].

Oscillatory expression patterns play a fundamental role in the timing of neuron differentiation. Goodfellow et al. [63] studied the negative FL involving miR-9 and Hes1 (Figure 1g), and they found out that miR-9, which is regulated by NF- $\kappa \mathrm{B}$ [66], controls the oscillatory pattern of Hes1 expression. Again, the presence of an miRNA sets a threshold on the amount of a TF, Hes1: Hes1-high ES cells commit to the mesodermal fate, whereas Hes1-low ES cells are induced to differentiate as neuron stem cells [67]. Another work by Moore and colleagues [68] dealt with the p53 oscillations observed in breast cancer cells upon DNA damage induction. Their results suggested that this oscillatory behaviour is the outcome of a network of nested FLs where miRNAs tune the amplitude of oscillations [11]. 
The circadian clock represents a fundamental oscillatory gene expression program that adapts cell activity according to environmental fluctuations, most notably light changes [69]. MiRNA mediated regulation contributes crucially in controlling and maintaining circadian clocks in animals [70]. More specifically, multiple experimental studies on Drosophila, mouse and human cells [69,71-73] have found out that circadian rhythms are governed by several miRNA mediated FLs. Although mathematical modelling studies concerning these circuits are currently lacking, miRNAs may play important roles in conferring robustness to circadian rhythms by controlling noise and oscillations, similarly to what has been observed in other contexts [11].

The issue of how the composition of miRNA pools with a common target influences the target regulation is still under debate. Furthermore, it raises the question of how the variability of miRNAs' abundances is achieved [44]. Interestingly, a newly published study [74] addresses the regulation of miRNA abundance during ageing, suggesting that it is controlled by an miRNA mediated FL. A global decline in miRNA amount with age has been shown, amongst others, in mice [75]. Inukai and coworkers [74] investigated the miRNA abundance decline in C. elegans and bioinformatically identified Alg-1/Argonaute as a regulator of global miRNA biogenesis. Alg-1 is putatively targeted by multiple miRNAs, yet experimental evidence showed that miR-71 post-transcriptionally represses Alg-1, establishing an FL that influences global miRNA abundance during ageing and concomitantly increases mRNA expression variability [74].

Several further works could be brought forward to highlight the role of miRNAs in carrying out diverse biological functions through FLs. For additional references, see [60,62,76-86].

\section{Double Negative Feedback Loops}

The double negative feedback loop (DNFL), also known as toggle switch, is a minimal motif that allows "all-or-none" outcomes, which makes it a suitable processing system in cell fate decision [16]. This kind of switch has also been found as a recurrent motif in the epi-miRNA network [17]. Several examples of miRNAs directly interacting with epigenetic machinery have been uncovered as reciprocally inhibitory switches [7]. For instance, the miR-29 family was shown to downregulate de novo DNA methylation by targeting two different methyltransferases. Interestingly, this miRNA cluster was hypermethylated itself in lung cancer, leading to overexpression of the same methyltransferases [87]. The involvement of many miRNAs in DNFLs, along with mathematical modelling and experimental proofs, supports the idea that miRNAs provide stability to alternative phenotypes in the presence of noise [88].

Since miRNAs play important roles in determining cell fate, their involvement in developmental contexts has been increasingly highlighted [89,90]. For instance, the Drosophila sense organ specification is achieved through an miRNA mediated DNFL [91]. Which cell will become part of the sense organ precursor (SOP) is determined stochastically, as it depends on the fluctuations in the level of the Senseless TF [42]. The DNFL linking miR-9a and Senseless (Figure 1c) is able to transform this noise into a switch: miR-9a levels are initially uniform among proneural cells, but as Senseless activity increases proneural gene expression in the SOP, $m i R-9 a$ is inhibited, while it still remains high in the surrounding cells: spatially exclusive miRNA domains are achieved [42]. Thus, the presence of $m i R-9 a$ ensures that only if Senseless levels overcome a threshold, cells commit to differentiation [42]. Indeed, the generation of mutant flies with extra sense organs has been observed in cases of $m i R-9 a$ loss-of-function [92]. A bistable switch is found also in the development of the C. elegans chemosensory neurons [42]. These are meant to be asymmetric on the left and right sides of the animal: cells must adopt one of two alternative phenotypes, ASEL and ASER [93]. Their initial state is unstable, and thus subject to fluctuations by noisy gene expression: the miR-273 family works together with TFs in a combination of loops that drives cells either to the left or the right type [42].

A DNFL between MALAT1 and miR-663a has recently been proposed as crucial in colon cancer cell functions [94], and the cancer associated fibroblast phenotype (CAF) has been shown to be tuned by miR-145 in a reciprocally inhibitory regulatory motif [95]. Another notable cancer related case is that of 
two miRNA mediated DNFLs that regulate the switch between epithelial and mesenchymal phenotypes in metastasis [96]. The epithelial to mesenchymal transition (EMT) provides cells with the ability to migrate, thus initiating metastasis. The reverse transition (MET) allows colonisation and growth of metastases [96]. The two opposite transitions are controlled respectively by the miR-34/SNAIL and miR-200/ZEB DNFLs, which have been proposed to function together as a bistable switch [97] (see Figure 1e). Meanwhile, $\mathrm{Lu}$ and colleagues [59] showed that the two DNFLs have separate roles in the switch: ZEB/miR-200 FL effectively carries out the EMT, whereas the SNAIL/miR-34 loop functions as a noise buffer of external signals that could lead to aberrant EMT activation.

Model analysis showed the existence of a third hybrid phenotype with both migratory and adhesion properties that could enable collective cell migration [98]. Experimental observations are consistent with tristability, suggesting that medium levels of miR-200 and ZEB lead to partial EMT [11]. Later, Huang and co-workers [61] connected the EMT network with the Rac1/Rhoa circuit that regulates transitions between the mesenchymal and the amoeboid phenotypes, as shown in Figure 1e. Model simulations showed that the transitions between individual and collective migration behaviours are regulated by miR-200 and miR-34: high levels of the miRNAs favour individual migration, thus likely inhibiting the formation of cancer metastasis [11]. One of the most recent developments concerning the role of miRNAs in the epithelial-mesenchymal transition has been pursued by Diepenbruck and colleagues [99]. Among a number of different miRNAs, they identified miR-1199-5 $p$ as a strong regulator of EMT. Furthermore, the results showed that miR-1199-5p acts in a DNFL with the previously mentioned TF ZEB1, and the behaviour of the circuit seems similar to that of the miR-200 family [99]. However, since miR-200 and miR-1199-5p only share a few common target genes, they likely carry out distinct functions during the transition [99].

In order to gain deeper insight into the biological functions of the DNFL, it is convenient to address the case of an miRNA and a TF mutually inhibiting each other, with upstream signals that can activate them, as depicted in Figure 3a. The example considered here has been investigated by Fang and co-workers in the context of the glioblastoma multiform human cancer [100]. SOX2, a gene notably related to glioblastoma, forms a DNFL with $m i R-145$. If miR-145 transcription is more induced than that of SOX2, its repressive strength over SOX2 will overcome the opposite inhibitory arm, thus leading to a state where only the miRNA is expressed and SOX2 is silenced (Figure 3b, miR-145-high expression levels). On the contrary, if SOX2 transcription is favoured over miR-145 transcription, the system collapses in the only-SOX2 state, where miR-145 is silenced [100] (Figure 3b, SOX2-high expression levels). Therefore, the DNFL embodies a simple mechanism that allows achieving bistable expression of its components.

\subsection{MicroRNA Mediated Feed-Forward Loops}

The FFL is one of the most represented three node network motifs in transcriptional networks [1,101]. Given its role in a wide range of biological processes [102-104] and its well established association with diseases (ranging from cancer $[17,105,106]$ to autoimmune diseases [107]), it is currently widely studied. Its general scheme is shown in Figure 2a, where the edges between the nodes represent the interactions between the molecules and may have either an activating or repressing function. The FFL is composed by a master regulator $A$ that regulates the expression of a target $C$ through two parallel paths: one direct and the other indirect. Through the latter, $A$ directly regulates the expression of a second player, $B$, which in turn regulates $C$ [2].

This type of circuit was firstly discovered in Escherichia coli [108] and then in several other organisms including yeast [1] and humans [101]. Later, different works showed an over-representation of FFLs mediated by microRNAs at a genome wide level [11,109-111], highlighting their importance in gene regulatory networks [112]. Specifically, in the case of mammalian genomes, these circuits play crucial roles in cell decision making, proliferation, development, and differentiation [6,102-104,113-115], as well as in DNA synthesis control and cell cycle regulation in both normal and cancer cells $[111,116,117]$. 


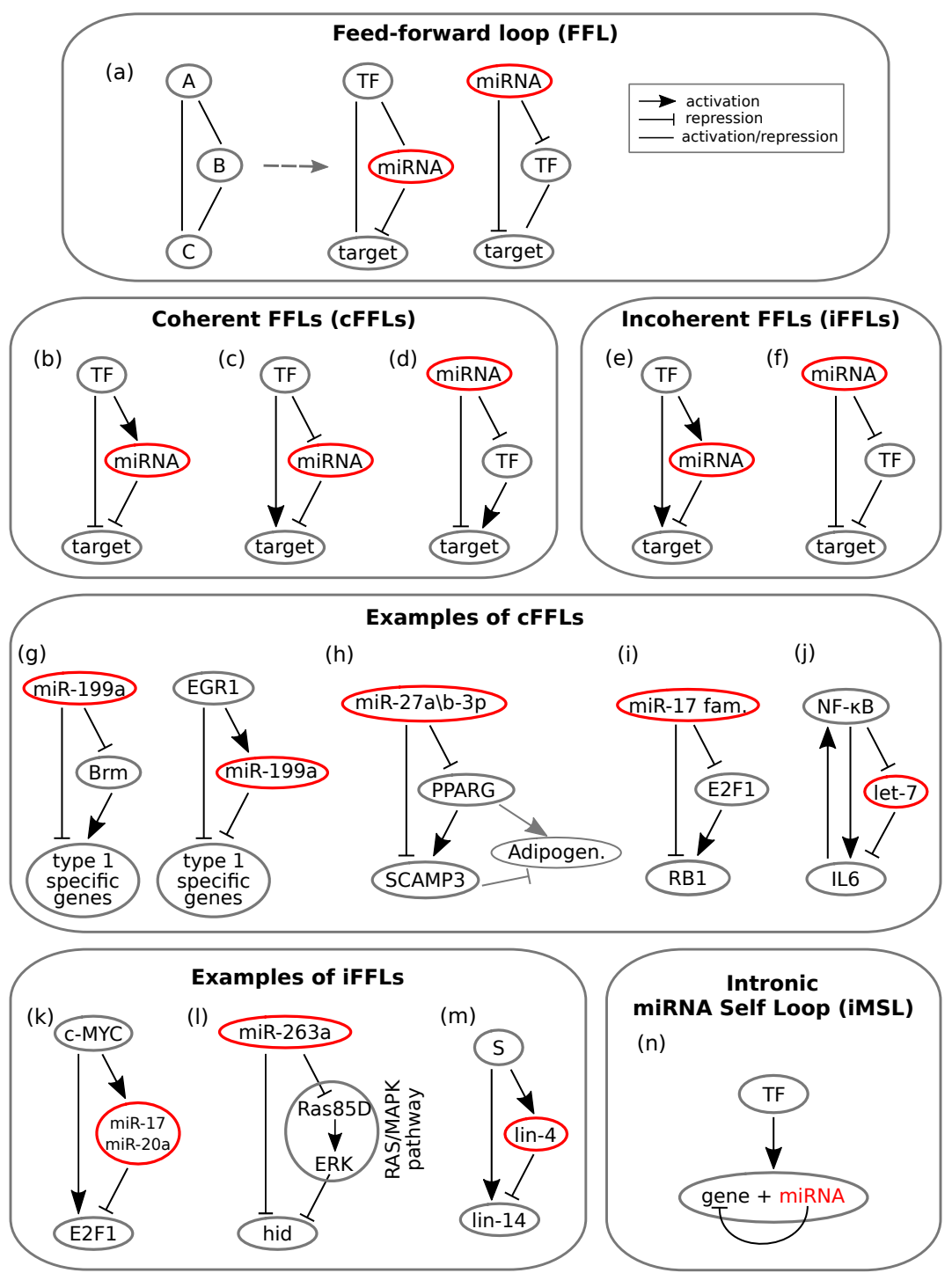

Figure 2. Schemes of feedforward loops (FFLs). Lines ending with an arrow indicate activation, whereas $\mathrm{T}$ ending lines indicate repression. Simple straight lines indicate that the interaction can either be activatory or repressive. (a) On the left, the general scheme of an FFL is represented. The master regulator gene $A$ regulates gene $C$ both directly (left path) and indirectly (right path) through the direct regulation of gene $C$. The central and right schemes synthesize all possible miRNA mediated FFLs: the miRNA can either play the role of a master regulator or standing in the intermediate regulator position. (b-d) Coherent miRNA mediated feedforward loops (cFFLs): regulatory paths make an overall positive sign. In (b) and (c), the TF plays the role of the master regulator, while in (d), such a role is assumed by the miRNA. (e,f) Incoherent miRNA mediated feed-forward loops (iFFLs): regulatory paths make an overall negative sign. In (e), the TF acts as the master regulator by activating both the miRNA and the target; in (f), the master regulator is the miRNA that represses both its targets. One of the targets then represses the other one. $(\mathrm{g}-\mathbf{j})$ Experimental examples of miRNA mediated cFFLs. (g) Two FFLs regulating the "all-or-none" expression of two groups of type 1 specific genes in human epithelial tumour cells. Adapted from [105]. (h) FFL mediated by miR-27a/b-3p regulating the expression of two target genes (PPARG and SCAMP3) in adipogenesis. The expression of PPARG upregulates SCAMP3. Adipogenesis has been found to be positively regulated by PPARG (grey arrow) and negatively regulated by PPARG (T-ended grey line). Adapted from [104]. (i) miRNA mediated FFL that fine tunes G0/G1-S transition during the cell cycle: the miR-17 family regulates both E2F1 and RB1, whose expression inhibits E2F1. Adapted from [117]. (j) Oncogenic transformation is regulated by miRNA let-7 through a cFFL: NF- $\kappa$ B regulates IL6 directly and indirectly through let-7. A feedback is 
present between IL6 and NF- $\kappa$ B. Adapted from [52]. (k-m) Experimental examples of miRNA mediated incoherent feed-forward loops (iFFLs). (k) iFFL that controls proliferative signal: the proto-oncogene $c-M Y C$ directly controls E2F1 transcription and indirectly controls its translation through activation of $m i R-17$ and miR-20a. Adapted from [118] (1) miR-263a controls cell crowding in the fly retina development, by regulating the pro-apoptotic gene head involution defective (hid) both directly and indirectly through the RAS/MAPK pathway. Adapted from [119]. (m) The miRNA lin-4 dampens expression oscillations of its target miRNA lin-14 through an FFL where both miRNAs are synchronously transcribed by a pulsatile source S. Adapted from [120]. (n) General scheme of an miRNA mediated intronic self-loop.

Different biological functions can emerge [42] depending on the interactions among the nodes of miRNA mediated FFLs, which are schematised in Figure 2a. FFLs are usually classified depending on the overall sign of their interactions, where the overall sign is calculated by multiplying the signs of each single path [2]. Based on this definition, the FFLs are classified as coherent (see Figure 2b-d) or incoherent (see Figure 2e,f) if the overall sign is either positive or negative, respectively. These two types of FFLs, as illustrated below, give rise to a wide range of features related to conferring robustness to the regulatory network in development and decision making.

\subsubsection{Coherent Feed-Forward Loops}

Mutually exclusive spatial expression of miRNA and its target characterises coherent FFLs (cFFLs) [102]. The case shown in Figure 2c, where a TF activates the target and represses the miRNA, thus effectively reducing the miRNA mediated target repression, suggests a fail-safe control role of the circuit, since the miRNA and target cannot be co-expressed. This has been experimentally proven in the case where either the TF or the miRNA was the master regulator of the circuit [104] (Figure 2d). Evidence showing the lack of co-expression of the two molecular species has been observed during the development of Drosophila [121], as well as in mice [122] and epithelial tumours [105].

In the example of epithelial tumours, Kobayashi and colleagues found that two miRNA mediated cFFLs regulate the expression of genes specific to one of the two phenotypes that human epithelial tumour cells may present, called type 1 [105]. These cFFLs involve the miRNA miR-199a, a catalytic subunit of a complex that regulates gene transcription (Brm) and the transcription factor EGR1; see Figure 2g. One of the two cFFLs has the miRNA as the master regulator, which downregulates type 1 specific genes both directly and indirectly through the downregulation of Brm, which in turn activates the genes. The other cFFL has EGR1 as the master regulator targeting the same type 1 specific genes both directly and indirectly through the activation of miR-199a. The activity of both loops leads to a mutually exclusive expression of miRNA and both its targets, and the expression of the type 1 specific genes occurs in an "all-or-none" manner.

Interesting examples that underline the importance of miRNA mediated cFFLs in defining spatio-temporal boundaries during differentiation have been also found in other human cells, like neurons [103] and human fat cells [104]. In a recent work focused on the formation of new human fat cells, the authors identified a novel cFFL involved in adipocyte differentiation [104]. The network motif is characterised by an miRNA $(m i R-27 a / b-3 p)$ playing the role of the master regulator of a transcription factor (peroxisome proliferator activated receptor gamma (PPARG)) and of a second target gene, the secretory carrier membrane protein 3 (SCAMP3). SCAMP3 is then positively regulated by PPARG; see Figure $2 \mathrm{~h}$. Since the miRNA controls the expression of both target genes, it could either prevent the excess (or lack) of target transcripts [11,123] or fine tune the ratio of the expression of the target genes, the latter predicted through stochastic modelling by Riba and colleagues [117]. Kulyté and collaborators evidenced opposite effects of PPARG and SCAMP3 on adipogenesis and on the functions related to adipocytes [104]. PPARG positively regulates adipogenesis, while SCAMP3 is an endogenous limiter of adipogenesis driven by PPARG. In other words, SCAMP3 negatively regulates the process. The regulation of adipogenesis is then fine tuned by the enrolment of PPARG and SCAMP3 within the cFFL mediated by miR-27a/b-3p. Thus, the net effect of such a loop is to tune 
the ratio between PPARG and SCAMP3, which could be relevant for maintaining a balance between hypertrophic and hyperplastic expansion of adipose tissue in obesity.

In [117], Riba and coworkers, in support of their theoretical findings about cFFL, presented a cFFL involving the $m i R-17$ family as the master regulator, E2F1 as the transcription factor and RB1 as the target gene, positively regulated by E2F1; see Figure $2 \mathbf{i}$. The motif is involved in the transition between the G0/G1 and S cell cycle phases, since E2F1 belongs to the family of genes that control such a transition. In phase G0, E2F1 and RB1 proteins are bound in complexes in almost all cells. In such a case, RB1 inhibits E2F1 functions and thus the cell cycle. On the contrary, in the presence of a stimulus that promotes cell division, the binding of E2F1 and RB1 is reduced, and the free-from-binding E2F1 proteins trigger the cell cycle. Thus, for a correct functioning of the transition between the two cell cycle phases, the relative concentration of the two genes must remain stable against fluctuations. The authors suggested that this is guaranteed by the miRNAs within the cFFL.

Another interesting example was shown in [52], where a cFFL limits the impact of noise in an oncogenic switch in response to an inflammatory signal [42]. The loop involves the transcription factor $\mathrm{NF}-\kappa \mathrm{B}$, which directly activates a mediator of the inflammatory response, the cytokine interleukin- 6 (IL6), and inhibits the miRNA let-7, which in turn represses IL6; see Figure 2j. Interestingly, the loop functions as an AND logic gate [3]: the activation of both the arms of the motif is necessary in order to reach the level of IL6 activity that allows cellular transformation. Such transformation is also aided by a positive feedback loop between NF- $\kappa$ B and IL6. The presence of let-7 prevents the noise in the activity of NF- $\kappa$ B or IL6 from triggering the NF- $\kappa$ B/IL6 feedback loop.

The role of miRNAs in conferring stability to differentiation processes when embedded in cFFLs has been also highlighted in [115], where the authors investigated the role of miR-7 in the differentiation of photoreceptor cells of Drosophila. The authors showed how two interlinked cFFLs with a TF as master regulator lead to a general expression stability. However, if the function of miR-7 is compromised, this stability is lost, and the system can be perturbed by temperature variations.

Several theoretical works discussed the role played by cFFLs in managing fluctuations [112,117,124,125]. In [125], Duk and collaborators found that cFFLs do not show absolute adaptation in response to external signals, i.e., the target expression level does not return to its baseline level after a transient external signal, neither if the signal is small. The ability to adapt to different environmental conditions is an important feature for living organisms, especially in noisy environments. The absence of adaptability suggests that cFFLs may be present only in those systems where a substantial change of the target expression, even if induced by small changes in the external condition, is not deleterious.

\subsubsection{Incoherent Feed-Forward Loops}

miRNAs may play a dual role in the presence of noise: on the one hand, they may generate and take advantage of fluctuations in order to perform defined tasks or to drive differentiation $[44,119,126,127]$; on the other hand, they can confer phenotypic robustness to gene expression by suppressing this variability $[88,122,123,128-130]$. In this framework, miRNA mediated circuits have been modelled as incoherent FFLs (iFFLs), as shown in Figure 2e,f. Stochastic modelling and numerical simulations were proven to be a powerful instrument to establish the role of miRNA in conferring robustness to these circuits by buffering gene expression fluctuations $[6,48,128,131-134]$.

Furthermore, while cFFLs promote the avoidance of the spatial co-expression of miRNA and their targets, iFFLs can promote the temporal phase shift between molecular species. Let us consider an iFFL where a TF acting as the master regulator induces the expression of both the miRNA and the target (Figure 2e). Even if activated by the same TF as its own target, miRNA expression appears to be delayed as a consequence of its own biogenesis [11,102]. Yet, once expressed, the miRNA inhibits the target, therefore inducing the temporal phase shift mentioned above.

An example of an miRNA mediated iFFL with a TF as the master regulator was described in the work of O'Donnell and colleagues [118]. The circuit involves the proto-oncogene $c-M Y C$ that encodes a TF responsible for the regulation of cell growth, proliferation and apoptosis. The authors found 
that $c-M Y C$ directly controls the transcription of E2F1 and indirectly limits E2F1 translation through the activation of the expression of a cluster of miRNAs; see Figure 2k. In [130], He and collaborators investigated an iFFL similar to that of O'Donnell et al. involving again MYC as the master regulator, the miR-17-92 cluster and E2F (E2F1 is a member of E2F family), and they showed that this type of loop effectively contributes to reducing gene expression fluctuations and therefore conferring to the miRNA the role of fine tuner of gene expression.

Analogously, Hilgers and collaborators [119] showed that the miRNAs miR-263a/b prevent programmed cell death of mechanosensory cells during fly retina development and confer robustness to the sensory organ specification (a role already proposed in [115] for the miRNA miR-7 involved both in a cFFL and an iFFL). A scheme of this iFFL is shown in Figure 21: miR-263a controls the expression of the pro-apoptotic gene head involution defective (hid) directly and indirectly through the RAS/MAPK pathway (composed in this case of Ras85D and ERK). With the sole direct path, the effect of the miRNA would be that of downregulating the expression of hid and thus its activity. However, this is mitigated by the indirect path through which miR-263a inhibits a hid repressor. The activity of the miRNA is thus to ensure robustness during apoptotic tissue pruning.

On the theoretical side, the work in [48] deeply studied the role of the iFFL in buffering gene expression fluctuations and compared it to other topologies by stochastic modelling and numerical simulations. Further works followed the one by Osella and colleagues $[112,124,125,135,136]$. More specifically, Duk and collaborators [124] confirmed the ability of the miRNA mediated iFFL to respond to a sudden change in the quantity of TF regulator with only a small deviation from the steady state. This allows highlighting the outstanding role of these regulatory motifs in those systems where changes in the target protein may cause serious consequences. However, this noise buffering property is evident only if the strength of the coupling between miRNA and target is tuned in a relatively small functional range. Outside this range, the circuit tends to either amplify fluctuations (strong coupling) or to produce a Poissonian statistics for the output variable (weak coupling) [137].

An important property of miRNA mediated iFFLs derived through mathematical modelling $[125,138]$ is their ability to adapt to transient signals, as purely transcriptional iFFLs [139]. Bleris and collaborators [140] studied the adaptability to changes in DNA template abundance through the development of synthetic transcriptional and post-transcriptional iFFLs in human embryonic kidney cells. They found that in all cases, the gene product levels adapted to changes. In addition to this, the post-transcriptional form showed a better adaptive behaviour, higher absolute levels of expression and lower levels of intrinsic fluctuations when compared to the purely transcriptional case. These results, in agreement with theoretical expectations [112,124,125], support the endogenous role of this motif in gene dosage compensation. Thus, the implementation of miRNA mediated iFFLs in synthetic networks would improve their robustness. Yet, the ability of the miRNA mediated iFFL to control protein noise can be altered in the presence of bursting inputs, as shown through stochastic modelling and numerical simulations in [137].

Similarly to what has been discussed regarding FLs, iFFLs can produce oscillatory outcomes under peculiar conditions. An interesting example, carried out by Kim and collaborators [120] and reviewed in [141], consists of an iFFL involved in the development of Caenorhabditis elegans. The timing of its developmental stages is stressed by oscillatory expression patterns. It is known that lin-4 oscillates according to these stages, whereas lin-14 displays a seemingly constant negative gradient throughout development of the wild-type worm. By investigating the relationship between lin-4 and lin-14, the authors found out that these two miRNAs are connected by an iFFL, as shown in Figures $2 \mathrm{~m}$ and $3 \mathrm{~h}$. By knocking down lin-4 transcription, that is silencing the inhibitory arm of the iFFL, they showed that lin-14 undergoes pulsatile dynamics as well. It is thus suggested that the pulsatile expression of lin-4 dampens the expression oscillations of its target lin-14, thereby ensuring its temporal gradient. Temporal expression of lin-14 in wild-type and in the lin-4 lacking mutant is qualitatively represented in Figure 3i. Moreover, the dampening is shown to be optimal if $l i n-4$ and lin-14 are transcribed together with in-phase pulses [120]. This could more generally represent a mechanism that serves to insulate 
key developmental players from upstream oscillatory or noisy signals. Several further examples can be brought forward to show that iFFLs are well suited to act as triggers for oscillatory systems and underline their importance in preventing the propagation of fluctuation in gene expression that might damage a developing organism [42,115].

iFFLs mediated by miRNAs have also been shown to detect gene expression fold changes [11,142]. Fold change detection is a feature related to Weber's law: the response of a system depends on relative rather than absolute changes in the input signal with respect to a basal level. Mathematical modelling [143] showed that iFFLs display such a property for a wide range of biochemical parameters. Having a fold detection mechanism may allow identical responses to external signals despite the cell-to-cell variability in the basal levels of master TFs.

\subsubsection{Intronic microRNA Mediated Self-Loops}

As mentioned above, the functions of many intronic miRNA appear to be correlated with those of the genes encoding the miRNAs themselves [144]. Using measures based on both annotation and experimental data, Lutter et al. suggested that many miRNAs link host and target gene activity in an either synergistic or antagonistic manner [145]. Here, we will focus on a minimal interaction circuit that sees intronic miRNAs as direct repressors of their host gene, that is the intronic miRNA mediated self-loop (iMSL), shown in Figure 2n. The iMSLs, which can be viewed as a compact version of an iFFL, can be represented by a master TF that regulates a single genomic locus encoding both the host gene and the miRNA, with the host gene in turn targeted by the miRNA [13]. Bioinformatic studies have found that iMSLs are significantly enriched in the human regulatory network [146], with approximately $20 \%$ of intronic miRNAs predicted to target their host gene [144]. This suggests that iMSLs can perform specific biological functions, potentially not achievable by other circuit topologies.

The question of the reason why intronic miRNA mediated gene autoregulation would be more suitable to fulfil certain tasks has been addressed both theoretically and experimentally $[13,135,147]$. Bosia and co-workers carried out a controlled mathematical comparison between the iMSL and other circuit topologies in order to highlight the iMSL's specificities in implementing particular functions. The results indicated that the iMSL can accelerate the synthesis of the host gene protein in response to an input signal and can delay its knockdown when the input signal drops. As other circuit topologies, it can efficiently buffer fluctuations of the upstream signal. In addition, the iMSL is able to implement complex functions such as a host gene expression obeying Weber's law, that is the response only depends on the input's fold change and not on the input's absolute value [13].

Strovas and colleagues [147] engineered a synthetic iMSL circuit composed of a doxycycline inducible fluorescent reporter self-regulated by its intronic miRNA miR-124 (Figure 3d). As a control, the authors engineered an analogous loop lacking the inhibitory arm (open-loop, Figure 3c). By integrating these circuit into the cells' genome and then measuring the fluorescent reporter amounts, they found that the iMSL showed adaptation (i.e., a transient protein expression pulse before returning to a lower steady-state level in response to a step-like increase in transcription rate), while the open-loop did not (Figure 3e). Moreover, the steady-state protein levels for the iMSL were independent of the size of the stimulus, thereby buffering protein production against changes in transcription (Figure 3f) and reducing cell-to-cell expression variability (Figure 3g). Yet, to this concern, a newly published study highlighted the dependence of the iMSL's noise buffering efficiency on the time scale of fluctuations [135].

A series of endogenous iMSLs have also been experimentally uncovered in small scale studies [148-154]. Chuang et al. [155] found miR-93-3p and MCM7 to be oppositely expressed in leiomyomas. Since the MCM7 gene encodes a protein that plays an important role in cell cycle, miR-93-3p may regulate replication and cell cycle progression through an iMSL. Another iMSL involving $m i R-26 b$ was found to control neuronal differentiation by post-transcriptional repression of its host gene, CTDSP2 [149]. However, the experimental validations of this kind of circuit are still in their infancy, as only a few examples of iMSLs have been confirmed to date [156]. 


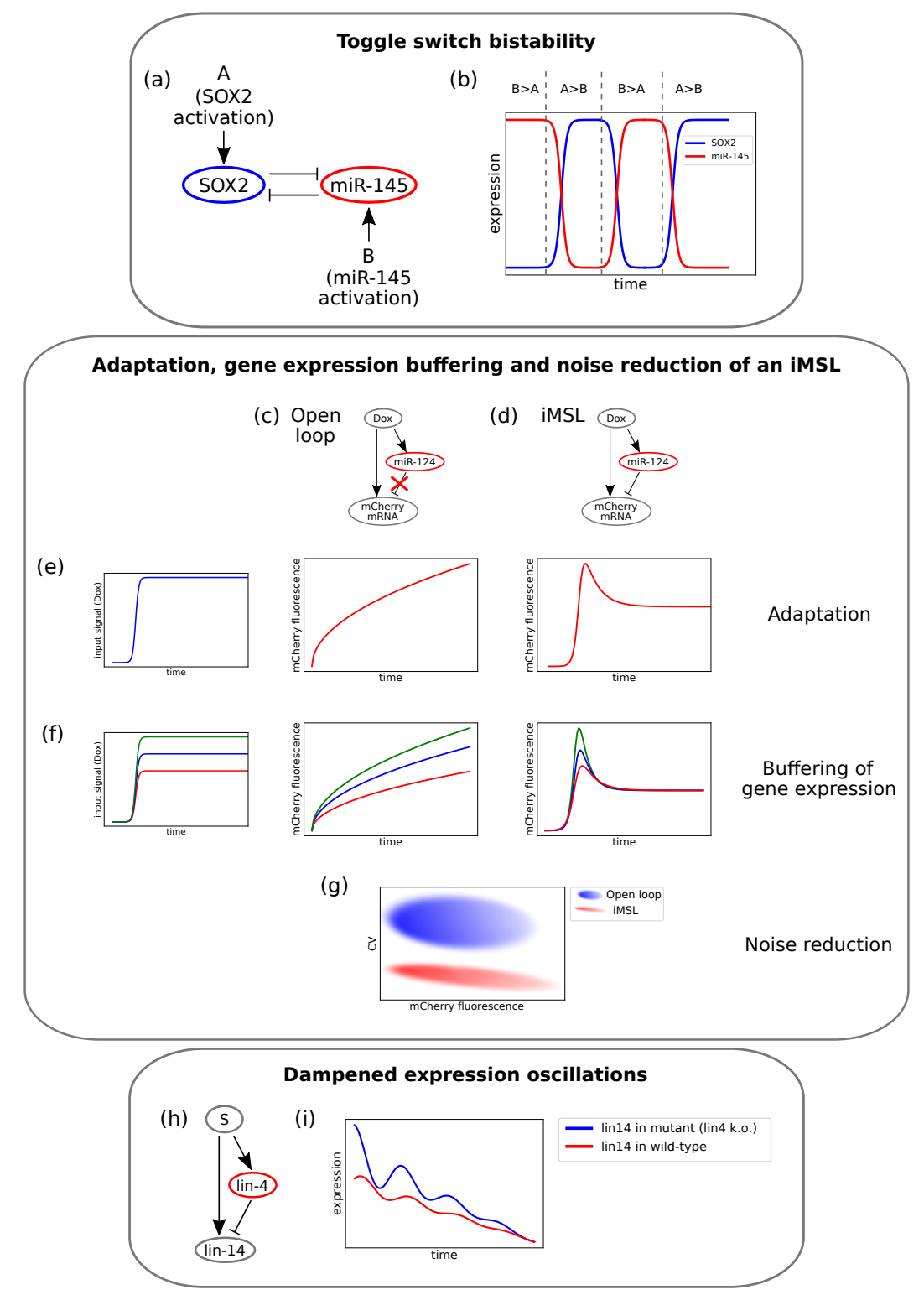

Figure 3. Examples of different experimental circuits showing properties theoretically predicted. (a) Example of the double negative feedback loop (DNFL) that displays bistability described in Fang et al. [100]. The circuit involves SOX2 and miR-145. (b) Bistable output of the DNFL. SOX2 temporal expression is depicted in blue and miR-145 temporal expression in red. The relative activation strengths determine whether the system settles in the high-miR-145 state or in the high-SOX2 state. Panels $(\mathbf{c}-\mathbf{g})$ report a schema of the results obtained by Strovas and colleagues [147] for an intronic miRNA mediated self-loop (iMSL). (c) The engineered open-loop. (d) The engineered iMSL. (e) Unlike the open-loop, the iMSL displays output adaptation. When a sudden input (left panel) is given to the system, the output fluorescence of the open-loop responds with an increasing trend (central panel), while the iMSL produces a pulse before reaching a lower steady-state level (right panel). (f) In the open-loop case (central panel), output levels depend on input signal intensities (left panel). On the contrary, the adaptive output level of the iMSL does not depend on the input size, and the iMSL buffers gene expression (right panel). (g) The iMSL displays noise reduction: for a given mean fluorescence value, the coefficient of variation (CV) is significantly lower in the iMSL case (in red) than in the open-loop (in blue). (h) The iFFL addressed by Kim and co-workers [120]. Lin-4 and lin-14 miRNAs are both transcribed by an upstream TF and lin-4 post-transcriptionally targets lin-14. (i) Lin-14 temporal expression in wild-type C. elegans (blue) and in mutant with lin-4 transcription knock-out (red). Lin-14 oscillation are dampened by lin-4 pulsatile expression (adapted from [120]). 
Summarising, the iMSL appears in general to be another useful way of maintaining cellular homoeostasis and conferring robustness to gene expression, coherently with the emerging idea of miRNAs as fine tuners of biological processes.

\section{MicroRNAs in Synthetic Circuits and Therapeutic Perspectives}

In the previous sections, we summarised and discussed the main properties of miRNA mediated gene regulatory networks, with particular attention to network motifs. Up to this point, the properties of endogenous circuits have been discussed. However, the ability of engineering synthetic regulatory networks, as well as integrating them in cells through plasmids or viral vectors gives the unique opportunity of investigating complex networks' behaviours under highly controlled conditions [157]. Besides representing a powerful experimental setup to test the predictability of theoretical results, these techniques, globally referred to as synthetic biology, give a chance to convey the first milestone results for therapeutic purposes.

Synthetic biology is based on a strongly interdisciplinary approach called cybergenetics [158], where the concepts of cybernetics are integrated with control theory, biological engineering and mathematical modelling in order to design synthetic circuits able to tune gene expression and thereby control cell functions $[158,159]$. The design of these circuitries able to sense multiple biological inputs, process complex information and finally give physiologically active responses is a long-standing challenge [160]. In particular, the reprogramming of genomic activities in mammalian cells could provide therapeutic strategies for a variety of diseases [161]. For instance, regulatory networks built to detect and selectively react to certain cellular conditions could exert anti-cancer actions [162].

A vast amount of studies have focused on the design of regulatory motifs controlled by transcriptional signals [160]. After purely TF mediated synthetic circuits, recent proposals rely on RNA interference (RNAi) logic; that is, the circuit's outcome depends on the interference of some RNA molecule with protein production. Specifically, engineered miRNAs are now widely used as circuit modules in order to exploit their well discussed regulatory features [163]. Generally, networks based on RNAi are constructed by coupling the binding of an input ligand to an RNA aptamer with the biogenesis of the RNAi [164]. In fact, many studies used a ligand that binds to the aptamer and thus causes conformational changes that inhibit miRNA biogenesis [165], thus affecting the production of an miRNA targeted protein [165].

Leisner et al. [160] proposed a general method for implementing transcriptional regulatory programs with RNAi circuits in mammalian cells by transfection. Their model has multiple TF inputs and a fluorescent protein output, and it is composed of different modules. In one module, each TF regulates a sensory miRNA gene. The mature miRNA converges on its mRNA target, which encodes an output protein tagged with a fluorescent dye that enables its quantification. By calibrating the features of constitutive regulator TF expressing vectors, miRNA expressing vectors and reporter plasmids encoding targets, the circuit's response can be tuned. This approach is presented as a basic starting point for more complex synthetic circuits that make use of RNAs [160].

An example of great interest for the purposes of this review is the work of Lillacci and collaborators [158], who reported new controllers of gene expression in mammalian cells containing post-transcriptional feedback and feed-forward regulation mediated by miRNAs. The authors designed and transfected in mammalian cells four controllers based on RNAi logic. The four implemented circuits were: (i) an open-loop (OL), (ii) a feedback loop (FL), (iii) an incoherent feed-forward loop (iFFL) and (iv) an hybrid of feedback and incoherent feed-forward loops (HYB). All of these circuits were implemented using plasmids with the same genes, and the only difference among the four was due to the regulatory relationships among them. The plasmids were composed by (i) a constitutively expressed yellow fluorescent protein (mCitrine) that represents a proxy for the amount of plasmid uptaken by the cell, (ii) a blue fluorescent synthetic controller (tetracycline-controller transactivator tTA-Advanced, called TA, fused to Cerulean) that induces the expression of both; a (iii) red-fluorescence protein of interest (DsRed) and (iv) an intronically encoded miRNA (miR-FF4). In order to implement 
different circuitry logics, the $3^{\prime}$-UTR regions of both TA and DsRed were engineered to contain or not binding sites for miR-FF4. The activity of TA over its downstream gene was externally tuned through doxycycline (DOX), which inhibits TA activity. Quantification of the expression levels has been performed through flow cytometry. Figure 4a reports the four loops.

\section{Examples of synthetic circuits}

(a)

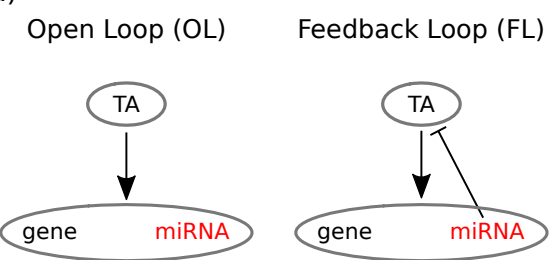

(b)
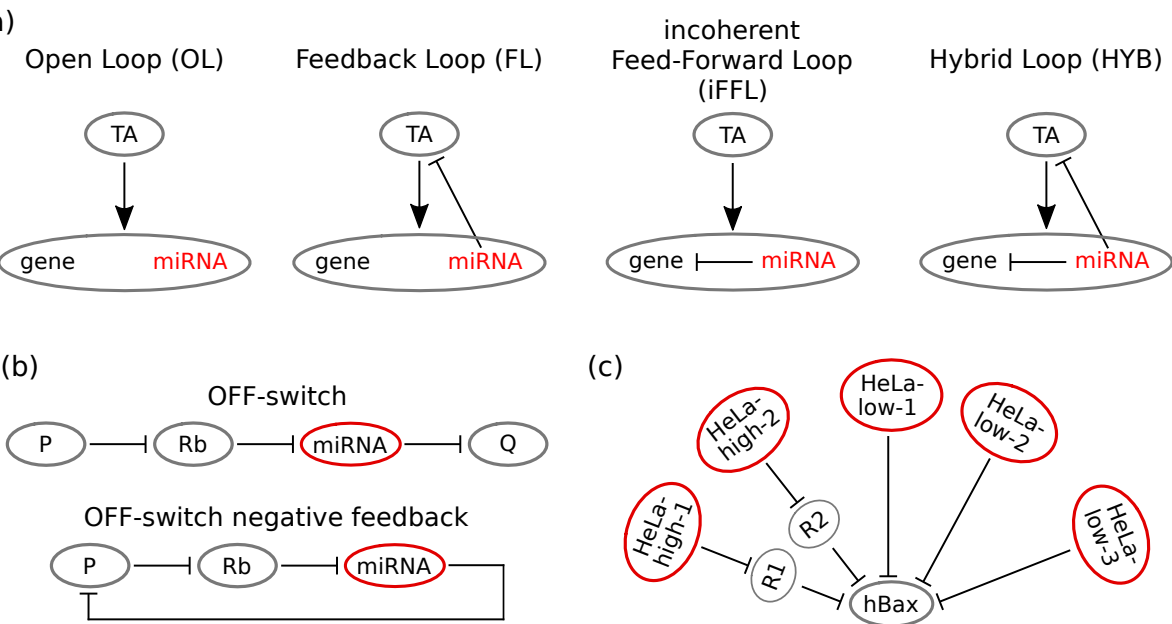

(c)

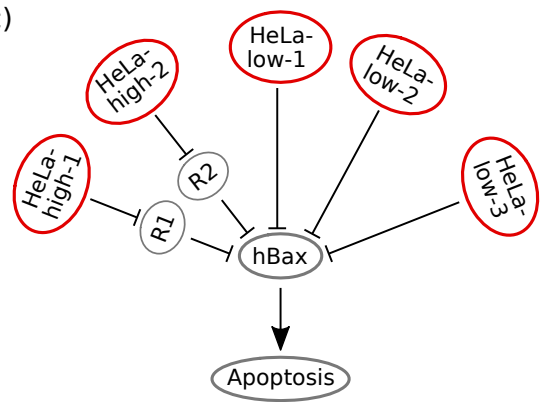

Figure 4. Examples of synthetic circuits. (a) Schemes of the four miRNA based controllers engineered in Lillacci et al. [158]. All the implemented circuits involve the same upstream regulator (tetracycline-controller transactivator TA), which targets a gene with intronic miRNA. In the open-loop (OL), the miRNA cannot bind the target. In the feedback loop (FL), TA is provided with miRNA binding sites; thus, a feedback is formed between the two species. In the incoherent feed-forward loop (iFFL), the gene is targeted by its intronic miRNA, thus forming an intronic miRNA mediated self-loop. In the hybrid loop (HYB), both the upstream regulator TA and the gene are targeted by the miRNA; thus, a hybrid-type loop is formed. (b) Scheme of the OFF switch implemented by Bloom et al. [165]. The ligand, an input protein $\mathrm{P}$, inhibits the ribozyme $(\mathrm{Rb})$, thereby preventing its cleavage action on the miRNA. Thus, miRNA biogenesis occurs, and the target gene $G$ is repressed. In the following phase, the OFF switch is shaped in such a way that the target coincides with the input protein itself, thus forming a controlled feedback loop that exhibits input level adaptation. (c) The identified miRNAs (two HeLa-high and three HeLa-low markers) target the same apoptotic gene, hBax. Adapted from [162].

The open-loop represents the standard inducible gene expression system and is engineered without miR-FF4 binding sites: TA therefore induces the expression of both the miRNA and the target. In the feedback loop instead, TA is provided with miRNA binding sites, therefore defining a feedback loop between the miRNA and its activator. The feed-forward loop is instead implemented via an intronic miRNA self-loop: miR-FF4 binding sites are on the $3^{\prime}$-UTR region of the DsRed; thus, both miRNA and its target are activated, and the miRNA represses the target. Finally, the hybrid loop (HYB) is the union of the last two loops: miRNA binding sites are present on both TA and DsRed.

Through such controllers, the main properties of the different loops discussed in the previous sections have been recovered. In particular, the authors showed that (i) the negative FL was able to confer robustness to TA dosage variability and improved output protein yield, (ii) the iFFL could tune the output expression and confer robustness to variability due to plasmid uptaking and (iii) the hybrid circuit showed ability in tuning the output, conferring robustness to plasmid uptaking variability, and showed adaptation to gene dosage. Moreover, the authors integrated such circuits in biologically interesting systems in order to improve their performances. For instance, the transfection of the FL into 
Chinese hamster ovary cells, usually implied in protein manufacturing, increases product levels by eliminating the burden effect induced by TA. Burdening represents indeed one of the main drawbacks in bioproduction affecting cell physiology: several bioengineering efforts have been made in order to limit this effect $[166,167]$. Moreover, the advantages of iFFL and HYB circuits have been observed by their transient transfection in human induced pluripotent stem cells. In the control situation, high levels of transgene expression were toxic to the cell line, and the presence of either iFFL or HYB allowed mitigating the toxic effect by regulating gene expression.

Inspired by the property of some miRNA mediated network motifs of preserving intracellular protein levels, cellular homoeostasis maintaining RNAi networks have been engineered [165]. A study by Bleris et al. [140] showed that the iFFL implements gene expression adaptation in mammalian cells. Specifically, the authors synthesised and tested FFLs based either on transcriptional or post-transcriptional regulation and observed that the output recovered adaptive levels in response to template abundance variation. Another interesting homoeostasis controlling system has been developed by Bloom and colleagues [165]. It consisted of a synthetic FL that combines a ligand responsive ribozyme switch and synthetic miRNA regulators. While most of RNAi devices function as ON-switches, that is the output protein's expression increases with ligand concentration, they developed a circuit that conversely increases silencing of the product by an miRNA in the presence of a ligand, thereby realising an RNAi based OFF-switch. This was possible by using a ribozyme $(\mathrm{Rb})$ whose presence ensures pri-miRNA formation and consequently silences the target gene. This OFF-switch was then used to target the ligand protein itself in an miRNA-controlled negative feedback that maintains constant protein levels in response to increases in the transcription rate [165], as shown in Figure 4b. This type of circuit can be a powerful way of stabilising cellular phenotypes, thus having useful therapeutic implications [165].

Of course, the well known simple network motifs can be combined in order to obtain better performing synthetic circuits [168]. Reeves and co-workers analysed the effects of combining different synthetic motifs on output adaptation and robustness: they combined an FFL with a negative feedback and showed that this network showed more robust dynamical adaptation properties than simple FL or FFL systems [168].

\section{MicroRNAs as Classifiers}

A network's ability to implement gene expression conditions can also be used for recognising cancer cells and triggering their apoptosis [164]. This idea lies behind the popular recent field of cell classifiers in synthetic biology $[157,169]$. A classifier is a regulatory network that detects sensory information from multiple molecular markers to determine if a cell is in a specific state and to produce consequently a biologically active protein output [162]. A major challenge for cancer therapy is to eliminate cancer cells without damaging the surrounding healthy ones [161]. In this view, cell classifiers appear to be great candidates to sense pathological cell conditions and to generate targeted therapeutic responses [161].

MiRNA responsive circuits are particularly useful for these purposes, as miRNA expression can be seen as a signature of the cell's condition and identity [159]. In this view, Xie and co-workers built a synthetic miRNA mediated circuit capable of distinguishing cervical cancer cells (HeLa cells) from other cell types. This circuit senses the expression intensities of a customisable series of endogenous miRNAs and activates a cellular response if these intensities match a pre-established profile [162]. More precisely, it can sense the expression of six different miRNAs and compare it to a previously constructed reference profile that is supposed to identify HeLa cells [162]. Depending on the output, it can then trigger the expression of an apoptosis inducing protein, hBax. A few miRNAs were identified as HeLa-low or HeLa-high markers. Then, the circuit's response function was modelled as a combination of logic AND/AND NOT operations on all miRNA inputs. This computation can be built in a network by choosing a homogeneous pool of miRNA targets (hBax expressing gene, Figure 4c) and implementing two feedforward loops with a threshold-like output expression. The constructed 
circuit performed as desired, the outcome being significantly higher in HeLa cells compared with the other cell lines used. Moreover, it selectively killed HeLa cells with respect to other cells [161].

Besides the usefulness of miRNA sensing in order to select apoptotic cells, Hirosawa et al. showed that endogenous miRNA profiles can be used by a regulatory switch for controlling genome editing [170]. A synthetic network can trigger effective biological programs by detecting complex intracellular signals. Nevertheless, therapeutic applications require the overcoming of challenges such as efficient in vivo DNA delivery to cells [162]. Moreover, as DNA delivery can lead to random genomic integration, RNA delivered circuits are preferable for medical purposes in terms of safety [159]. A recently published work [159] used an all-RNA system that provides an alternative to DNA delivery. A multiple miRNA sensing circuit for logic computation in mammalian cells was constructed using an RNA-only delivery approach. This kind of RNA based logic circuit with RNA binding proteins tunes the output's production with the aim of selectively controlling cell death pathways. Five logic gates (AND, OR, NAND, NOR, XOR) were created and validated by measuring the output's net fold-change, and all circuits displayed statistically significant performance [159]. Specifically, a two-input AND circuit involving an apoptotic gene led to precise elimination of target cells.

More generally, circuit topology can be optimally shaped in order to generate the best candidate circuits for precise cell targeting and avoid the extensive use of empirical trials. This issue has been addressed by Mohammadi et al. in a recent work [171] by using again miRNA expression datasets as phenotype markers. In this study, a computational method was presented for designing experimentally feasible miRNA mediated circuits that can distinguish cells according to various actual classification problems [171]. A unique circuit specification comprises the set of inputs, the network topology, and a set of biochemical parameters such as rate constants and initial conditions that determine its dynamics [171]. Obviously, optimisation is burdened by the combinatorial explosion of the number of possible circuits. A two step approach can be used to solve this issue: first, an optimised set of biochemical parameters is derived over a set of different topologies; second, the circuit topology is optimised for each task using the globally inferred parameters obtained in the first step [171]. In sum, this work provides a method that identifies a single circuit with optimal classification performance, that is producing the highest output levels in target cells with respect to all other cells [171].

Yet, the optimisation of single circuit classifiers often suggests the design of highly complex structures that are difficult to build in the real world [157]. A newly published study by Nowicka and colleagues made use of the so-called distributed classifiers (DC), that is sets of small and simple network motifs that function in an integrated manner and produce a collective response according to a threshold function [157]. Specifically, an initial set of simple networks is trained using a machine learning algorithm, and as a consequence, low-performance circuits are withdrawn. By using real cancer data, it was shown that such a set of simple classifiers performs better in terms of classification and is more robust with respect to a single complex circuit, as the integration of individual outputs compensates for single circuit errors. This suggests that DCs may also manage noise in the input data better than single network classifiers [157].

More recently, the achievements of synthetic circuits have gone beyond the simple cell type recognition thanks to a new work by Endo and colleagues [172], which showed that their mRNA based circuits are not only capable of discriminating human cells, but they can also track their change when they differentiate. Thus, their work opened the possibility to make decisions also based on dynamical information on the intracellular state.

Cell dynamics tracking of course opens questions about how to reprogram differentiated cells to pluripotent cells [173] or how to control stem cell differentiation precisely [174]. Yet, one of the greatest challenges for clinical applications is that of ensuring that engineered cells do not present side effects to humans [161]. To lower this risk, host cells should be replaced by primary cells or stem cells isolated directly from the patient. Thus, induced pluripotent stem cells may pave the way to personalised medicine by allowing the generation of patient specific cells and tissues that do not have to be derived from embryos [173]. 
As discussed, miRNA mediated synthetic networks open a wide range of useful biomedical possibilities. Future perspectives of miRNA mediated synthetic motifs involve the development of circuits with high biocomputing capacity, able to integrate a large number of diverse inputs in order to provide always more sophisticated biological responses.

\section{Conclusions}

The network motifs discussed so far were generally considered as single blocks composed by a small number of interacting units. Despite their simplicity, we showed how they are able to give rise to complex biological functions linked to noise processing. However, by enlarging the picture, they represent single building blocks of the bigger and more complex network that regulates gene expression in eukaryotes.

As already mentioned in some of the examples reported in the previous sections $[52,115,130]$, the regulatory output and thus the role of the single players is often the result of the interconnection of some of the elementary circuits, like the combination of a feed-forward loop with a feedback loop [52,130]. For instance, in [130], an interplay between miRNA mediated feedback and feed-forward loops that share some of their components may provide the miRNA with the dual role of oncogene and tumour suppressor. In addition to this, a specific biological feature (see for example the ability of suppressing noise) may be achieved through different pathways, suggesting, from a mathematical point of view, the non-uniqueness of the solution [11,112].

The NF- $\kappa$ B regulatory network displays a striking example of this behaviour. As discussed, NF- $\kappa \mathrm{B}$ is involved in a series of interconnected miRNA mediated loops that regulate inflammatory response. However, the regulatory relationships between miRNAs and NF- $\kappa$ B go well beyond the few loops shown so far. Markopoulos et al. [175] reviewed the connections of NF- $\kappa$ B with several miRNAs that modulate inflammation in cancer and discussed the role of each of these connections. For instance, an NF- $\kappa \mathrm{B} / m i R-155$ network appears to calibrate the intensity and duration of inflammation, whereas the NF- $\kappa \mathrm{B} / m i R-21$ loop displays an amplification behaviour that can lead from inflammation to cancer [175]. Furthermore, Rokavec and colleagues reviewed the roles of different NF- $\kappa$ B involving circuits in linking inflammatory conditions to cancer initiation and progression [176]. Since we cannot entirely report the described NF- $\kappa$ B network, an idea of its importance and ubiquity can be caught from the impressive number of $\mathrm{NF}-\kappa \mathrm{B} / \mathrm{miRNA}$ interactions: genomic data provide a list of 162 miRNAs regulating NF- $\kappa B$ and, vice versa, 40 miRNAs targeted by NF- $\kappa$ B [175]. In sum, it is likely that the net outcome of NF- $k B^{\prime} s$ dense network can either favour cancer development or limit it. Moreover, some miRNAs that are regulated by NF- $\kappa$ B in turn regulate the already mentioned p53 involved in breast cancer development and vice versa [177]. Thus, the NF- $\kappa$ B and the p53 interactomes are connected as well, and together, they may determine the neoplastic transformation of a cell or oppositely tumour suppression [177].

By looking more closely at the p53 interactions with miRNAs, again, a number of p53 regulated and p53 regulating miRNAs have been identified. These miRNAs appear to be involved in cell cycle regulation, stemness regulation and cell survival, amongst others. Focusing on their cancer related roles, a part of these miRNAs acts as tumour suppressors, while some of them play oncogenic roles in the intricate p53/miRNA network [178]. An outstanding example among the p53 related miRNAs is represented by the miR-34 family members, which have been found as the prevailing p53 induced miRNAs, as reviewed in [179]. Coherently with the well known relation of p53 with several types of tumours, this miRNA family has been implicated in diverse cancer related functions, such as proliferation, apoptosis, EMT, migration, and metastasis, as summarized by Rokavec and colleagues [179] and Yamakuchi et al. [180].

Furthermore, the epithelial-to-mesenchymal transition has been shown to be also connected to NF- $\kappa$ B. Indeed, the inflammatory signals that activate NF- $\kappa$ B also feed back on EMT inducing TFs, such as the already mentioned SNAIL and ZEB. For a review, see [181]. The NF- $k B$ and p53 interactomes only give an insight into the importance of considering the ensemble of simple interactions 
as a whole. In sum, the functions of single motifs must be taken collectively into account in order to predict global biological responses, especially for therapeutic aims.

By zooming out from the simple network motifs, these may be part of a bigger and more complex regulatory network composed by the miRNAs and all their target genes. Indeed, the miRNA-target interaction has a combinatorial nature: one miRNA can regulate several targets, and these in turn can be regulated by several miRNAs. Such a feature, coupled with the molecular sequestration mechanism of miRNA-target binding, may induce cross-talks among the targets that compete to bind to the same miRNA pool, giving rise to a layer of post-transcriptional cross-regulation recently called the ceRNA (competing endogenous RNA) effect [22]. The number of binding sites in ceRNA candidates is inversely related to the effective concentration of free targeting miRNAs, making the shared miRNA binding sites cross-talk hubs of gene interactions. In light of this, the deletion of shared miRNAs by ceRNAs and the competition for binding represents an indirect mechanism for cross-regulation and interaction among RNA species [11].

Some examples in the literature show functional effects of ceRNAs in contexts like cancer [19,26], cell differentiation [182] and self-renewal of embryonic stem cells [183]. However, up to now, the broader characterisation of ceRNA properties has been performed under a theoretical point of view both through stochastic modelling and in silico simulations [20,21,45,184,185], as reviewed in [186]. Quantitative experiments that allow testing theoretical predictions are much more recent and still limited, and the best way to address such issues experimentally seems the use of synthetic biology. The study of engineered genetic circuits [187], in particular through the use of bidirectional reporters $[18,188,189]$, allows investigating such complex regulation under controlled conditions in an isolated biological setting. A similar characterisation in those systems with evidence of functional ceRNAs $[26,182,183]$ would be interesting, but it is still lacking.

Author Contributions: All the authors wrote and revised the manuscript.

Funding: This work was supported by the Francis Crick Institute, which receives its core funding from Cancer Research U.K. (FC001317), the U.K. Medical Research Council (FC001317) and the Wellcome Trust (FC001317) to S.G.

Conflicts of Interest: The authors declare no conflict of interest. The funders had no role in the writing of the manuscript.

\section{Abbreviations}

MDPI Multidisciplinary Digital Publishing Institute

DOAJ Directory of open access journals

TLA Three letter acronym

LD linear dichroism

\section{References}

1. Milo, R.; Shen-Orr, S.; Itzkovitz, S.; Kashtan, N.; Chklovskii, D.; Alon, U. Network motifs: Simple building blocks of complex networks. Science 2002, 298, 824-827. [CrossRef] [PubMed]

2. Alon, U. An Introduction to Systems Biology: Design Principles of Biological Circuits; Chapman and Hall/CRC: London, UK, 2006.

3. Mangan, S.; Alon, U. Structure and function of the feed-forward loop network motif. Proc. Natl. Acad. Sci. USA 2003, 100, 11980-11985. [CrossRef] [PubMed]

4. François, P.; Hakim, V. Design of genetic networks with specified functions by evolution in silico. Proc. Natl. Acad. Sci. USA 2004, 101, 580-585. [CrossRef] [PubMed]

5. Grigolon, S.; Bravi, B.; Martin, O.C. Responses to auxin signals: An operating principle for dynamical sensitivity yet high resilience. R. Soc. Open Sci. 2018, 5, 172098. [CrossRef]

6. Tsang, J.; Zhu, J.; Van Oudenaarden, A. MicroRNA mediated feedback and feedforward loops are recurrent network motifs in mammals. Mol. Cell 2007, 26, 753-767. [CrossRef] 
7. Osella, M.; Riba, A.; Testori, A.; Corà, D.; Caselle, M. Interplay of microRNA and epigenetic regulation in the human regulatory network. Front. Genet. 2014, 5, 345. [CrossRef]

8. Gebert, L.F.; MacRae, I.J. Regulation of microRNA function in animals. Nat. Rev. Mol. Cell Biol. 2019, 20, 21-37. [CrossRef]

9. Cai, Y.; Yu, X.; Hu, S.; Yu, J. A brief review on the mechanisms of miRNA regulation. Genom. Proteom. Bioinform. 2009, 7, 147-154. [CrossRef]

10. Luo, Z.; Xu, X.; Gu, P.; Lonard, D.; Gunaratne, P.H.; Cooney, A.J.; Azencott, R. miRNA regulatory circuits in ES cells differentiation: A chemical kinetics modeling approach. PLoS ONE 2011, 6, e23263. [CrossRef]

11. Lai, X.; Wolkenhauer, O.; Vera, J. Understanding microRNA mediated gene regulatory networks through mathematical modelling. Nucleic Acids Res. 2016, 44, 6019-6035. [CrossRef]

12. Galatenko, V.V.; Galatenko, A.V.; Samatov, T.R.; Turchinovich, A.A.; Shkurnikov, M.Y.; Makarova, J.A.; Tonevitsky, A.G. Comprehensive network of miRNA-induced intergenic interactions and a biological role of its core in cancer. Sci. Rep. 2018, 8, 2418. [CrossRef] [PubMed]

13. Bosia, C.; Osella, M.; El Baroudi, M.; Corà, D.; Caselle, M. Gene autoregulation via intronic microRNAs and its functions. BMC Syst. Biol. 2012, 6, 131. [CrossRef] [PubMed]

14. Gromak, N. Intronic microRNAs: A crossroad in gene regulation. Biochem. Soc. Trans. 2012, 40, 759-761. [CrossRef] [PubMed]

15. Ellwanger, D.C.; Büttner, F.A.; Mewes, H.W.; Stümpflen, V. The sufficient minimal set of miRNA seed types. Bioinformatics 2011, 27, 1346-1350. [CrossRef]

16. Riba, A.; Osella, M.; Caselle, M.; Zavolan, M. Biophysical analysis of miRNA-dependent gene regulation. In Systems Biology. RNA Technologies; Rajewsky, N., Jurga, S., Barciszewski, J., Eds; Springer: Cham, Switzerland, 2018; pp. 257-273.

17. Re, A.; Caselle, M.; Bussolino, F. MicroRNA mediated regulatory circuits: Outlook and perspectives. Phys. Biol. 2017, 14, 045001.

18. Mukherji, S.; Ebert, M.S.; Zheng, G.X.Y.; Tsang, J.S.; Sharp, P.A.; van Oudenaarden, A. MicroRNAs can generate thresholds in target gene expression. Nat. Genet. 2011, 43, 854-859. [CrossRef]

19. Ala, U.; Karreth, F.A.; Bosia, C.; Pagnani, A.; Taulli, R.; Léopold, V.; Tay, Y.; Provero, P.; Zecchina, R.; Pandolfi, P.P. Integrated transcriptional and competitive endogenous RNA networks are cross-regulated in permissive molecular environments. Proc. Natl. Acad. Sci. USA 2013, 110, 7154-7159. [CrossRef]

20. Bosia, C.; Pagnani, A.; Zecchina, R. Modelling Competing Endogenous RNA Networks. PLoS ONE 2013, 8, e66609, doi:10.1371/journal.pone.0066609. [CrossRef]

21. Figliuzzi, M.; Marinari, E.; De Martino, A. MicroRNAs as a selective channel of communication between competing RNAs: A steady-state theory. Biophys. J. 2013, 104, 1203-1213. [CrossRef]

22. Salmena, L.; Poliseno, L.; Tay, Y.; Kats, L.; Pandolfi, P. A ceRNA Hypothesis: The Rosetta Stone of a Hidden RNA Language? Cell 2011, 146, 353-358, doi:10.1016/j.cell.2011.07.014. [CrossRef]

23. Tay, Y.; Rinn, J.; Pandolfi, P. The multilayered complexity of ceRNA crosstalk and competition. Nature 2014, 7483, 344-352. [CrossRef] [PubMed]

24. Chi, S.; Zang, J.; Mele, A.; Darnell, R. Argonaute HITS-CLIP decodes microRNA-mRNA interaction maps. Nature 2009, 7254, 479-486. [CrossRef] [PubMed]

25. Licatalosi, D.; Mele, A.; Fak, J.; Ule, J.; Kayikci, M.; Chi, S.; Clark, T.; Schweitzer, A.; Blume, J.; Wang, X.; et al. HITS-CLIP yields genome-wide insights into brain alternative RNA processing. Nature 2006, 7221, 464-469. [CrossRef] [PubMed]

26. Poliseno, L.; Salmena, L.; Zhang, J.; Carver, B.; Haveman, W.J.; Pandolfi, P.P. A coding-independent function of gene and pseudogene mRNAs regulates tumour biology. Nature 2010, 465, 1033-1038. [CrossRef] [PubMed]

27. Yang, A.; Furber, K.; Ji, S. Pseudogenes regulate parental gene expression via ceRNA network. J. Cell. Mol. Med. 2017, 1, 185-192.

28. Hansen, T.B.; Jensen, T.I.; Clausen, B.H.; Bramsen, J.B.; Finsen, B.; Damgaard, C.K.; Kjems, J. Natural RNA circles function as efficient microRNA sponges. Nature 2013, 495, 384-388. [CrossRef] [PubMed]

29. Hausser, J.; Syed, A.P.; Selevsek, N.; Van Nimwegen, E.; Jaskiewicz, L.; Aebersold, R.; Zavolan, M. Timescales and bottlenecks in miRNA-dependent gene regulation. Mol. Syst. Biol. 2013, 9, 711. [CrossRef]

30. Zhang, B.; Pan, X.; Cobb, G.P.; Anderson, T.A. microRNAs as oncogenes and tumour suppressors. Dev. Biol. 2007, 302, 1-12. [CrossRef] 
31. Palanichamy, J.K.; Rao, D.S. miRNA dysregulation in cancer: Towards a mechanistic understanding. Front. Genet. 2014, 5, 54. [CrossRef]

32. Sato, F.; Tsuchiya, S.; Meltzer, S.J.; Shimizu, K. MicroRNAs and epigenetics. FEBS J. 2011, 278, $1598-1609$. [CrossRef]

33. Costinean, S.; Zanesi, N.; Pekarsky, Y.; Tili, E.; Volinia, S.; Heerema, N.; Croce, C. Pre-B cell proliferation and lymphoblastic leukemia/high-grade lymphoma in E $\mu$-miR155 transgenic mice. Proc. Natl. Acad. Sci. USA 2006, 18, 7024-7029. [CrossRef] [PubMed]

34. Esquela-Kerscher, A.; Trang, P.; Wiggins, J.; Patrawala, L.; Cheng, A.; Ford, L.; Weidhaas, J.; Brown, D.; Bader, A.; Slack, F. The let-7 microRNA reduces tumour growth in mouse models of lung cancer. Cell Cycle 2008, 6, 759-764. [CrossRef] [PubMed]

35. Hatley, M.; Patrick, D.; Garcia, M.; Richardson, J.; Bassel-Duby, R.; van Rooij, E.; Olson, E.N. Modulation of K-Ras-dependent lung tumourigenesis by MicroRNA-21. Cancer Cell 2010, 3, 282-293. [CrossRef] [PubMed]

36. Mann, M.; Mehta, A.; Zhao, J.; Lee, K.; Marinov, G.; Garcia-Flores, Y.; Lu, L.; Rudensky, A.; Baltimore, D. An NF- $\kappa$ B-microRNA regulatory network tunes macrophage inflammatory responses. Nat. Commun. 2017, 8, 851, doi:10.1038/s41467-017-00972-z. [CrossRef] [PubMed]

37. Schmiedel, J.M.; Klemm, S.L.; Zheng, Y.; Sahay, A.; Blüthgen, N.; Marks, D.S.; van Oudenaarden, A. MicroRNA control of protein expression noise. Science 2015, 348, 128-132. [CrossRef]

38. M’baya-Moutoula, E.; Louvet, L.; Molinié, R.; Guerrera, I.C.; Cerutti, C.; Fourdinier, O.; Nourry, V.; Gutierrez, L.; Morlière, P.; Mesnard, F.; et al. A multi-omics analysis of the regulatory changes induced by miR-223 in a monocyte/macrophage cell line. Biochim. Biophys. Acta (BBA)-Mol. Basis Dis. 2018, 1864, 2664-2678. [CrossRef]

39. Hart, M.; Walch-Rückheim, B.; Krammes, L.; Kehl, T.; Rheinheimer, S.; Tänzer, T.; Glombitza, B.; Sester, M.; Lenhof, H.P.; Keller, A.; et al. miR-34a as hub of T cell regulation networks. J. Immunother. Cancer 2019, 7, 187. [CrossRef]

40. Calsina, B.; Castro-Vega, L.J.; Torres-Pérez, R.; Inglada-Pérez, L.; Currás-Freixes, M.; Roldán-Romero, J.M.; Mancikova, V.; Letón, R.; Remacha, L.; Santos, M.; et al. Integrative multi-omics analysis identifies a prognostic miRNA signature and a targetable miR-21-3p/TSC2/mTOR axis in metastatic pheochromocytoma/paraganglioma. Theranostics 2019, 9, 4946. [CrossRef]

41. Castro-Vega, L.J.; Letouzé, E.; Burnichon, N.; Buffet, A.; Disderot, P.H.; Khalifa, E.; Loriot, C.; Elarouci, N.; Morin, A.; Menara, M.; et al. Multi-omics analysis defines core genomic alterations in pheochromocytomas and paragangliomas. Nat. Commun. 2015, 6, 6044. [CrossRef]

42. Herranz, H.; Cohen, S.M. MicroRNAs and gene regulatory networks: Manageing the impact of noise in biological systems. Genes Dev. 2010, 24, 1339-1344. [CrossRef]

43. Hu, T.; Wei, L.; Li, S.; Cheng, T.; Zhang, X.; Wang, X. Single cell transcriptomes reveal characteristics of miRNA in gene expression noise reduction. bioRxiv 2018, 465518, doi:10.1101/465518. [CrossRef]

44. Garg, S.; Sharp, P.A. Single-cell variability guided by microRNAs. Science 2016, 352, 1390-1391. [CrossRef] [PubMed]

45. Del Giudice, M.; Bo, S.; Grigolon, S.; Bosia, C. On the role of extrinsic noise in microRNA mediated bimodal gene expression. PLoS Comput. Biol. 2018, 14, e1006063. [CrossRef] [PubMed]

46. Gosline, S.J.; Gurtan, A.M.; JnBaptiste, C.K.; Bosson, A.; Milani, P.; Dalin, S.; Matthews, B.J.; Yap, Y.S.; Sharp, P.A.; Fraenkel, E. Elucidating microRNA regulatory networks using transcriptional, post-transcriptional, and histone modification measurements. Cell Rep. 2016, 14, 310-319. [CrossRef] [PubMed]

47. Kærn, M.; Elston, T.C.; Blake, W.J.; Collins, J.J. Stochasticity in gene expression: From theories to phenotypes. Nat. Rev. Genet. 2005, 6, 451-464. [CrossRef] [PubMed]

48. Osella, M.; Bosia, C.; Corá, D.; Caselle, M. The Role of Incoherent MicroRNA-Mediated Feedforward Loops in Noise Buffering. PLoS Comput. Biol. 2011, 7, e1001101, doi:10.1371/journal.pcbi.1001101. [CrossRef]

49. Chakraborty, M.; Hu, S.; Del Giudice, M.; De Martino, A.; Bosia, C.; Sharp, P.A.; Garg, S. Networks of enhancers and microRNAs drive variation in cell states. bioRxiv 2019, 668145.

50. Cheng, C.; Yan, K.K.; Hwang, W.; Qian, J.; Bhardwaj, N.; Rozowsky, J.; Lu, Z.J.; Niu, W.; Alves, P.; Kato, M.; et al. Construction and analysis of an integrated regulatory network derived from high-throughput sequencing data. PLoS Comput. Biol. 2011, 7, e1002190. [CrossRef] 
51. Heo, I.; Joo, C.; Cho, J.; Ha, M.; Han, J.; Kim, V.N. Lin28 mediates the terminal uridylation of let-7 precursor MicroRNA. Mol. Cell 2008, 32, 276-284. [CrossRef]

52. Iliopoulos, D.; Hirsch, H.A.; Struhl, K. An epigenetic switch involving NF- $\kappa$ B, Lin28, Let-7 MicroRNA, and IL6 links inflammation to cell transformation. Cell 2009, 139, 693-706. [CrossRef]

53. Gunaratne, P.H. Embryonic stem cell microRNAs: Defining factors in induced pluripotent (iPS) and cancer (CSC) stem cells? Curr. Stem Cell Res. Ther. 2009, 4, 168-177. [CrossRef] [PubMed]

54. Yin, J.; Zhao, J.; Hu, W.; Yang, G.; Yu, H.; Wang, R.; Wang, L.; Zhang, G.; Fu, W.; Dai, L.; et al. Disturbance of the let-7/LIN28 double-negative feedback loop is associated with radio-and chemo-resistance in non-small cell lung cancer. PLoS ONE 2017, 12, e0172787. [CrossRef] [PubMed]

55. Peng, Y.; Croce, C.M. The role of MicroRNAs in human cancer. Signal Transduct. Targeted Ther. 2016, 1, 15004. [CrossRef] [PubMed]

56. Biyashev, D.; Qin, G. E2F and microRNA regulation of angiogenesis. Am. J. Cardiovasc. Dis. 2011, 1, 110. [PubMed]

57. Emmrich, S.; Pützer, B.M. Checks and balances: E2F-microRNA crosstalk in cancer control. Cell Cycle 2010, 9, 2555-2567. [CrossRef] [PubMed]

58. Zargar, S.; Tomar, V.; Shyamsundar, V.; Vijayalakshmi, R.; Somasundaram, K.; Karunagaran, D. A feedback loop between microRNA 155 (miR-155), programmed cell death 4, and activation protein 1 modulates the expression of miR-155 and tumourigenesis in tongue cancer. Mol. Cell. Biol. 2019, 39, e00410-18. [CrossRef]

59. Lu, M.; Jolly, M.K.; Levine, H.; Onuchic, J.N.; Ben-Jacob, E. MicroRNA-based regulation of epithelial-hybrid-mesenchymal fate determination. Proc. Natl. Acad. Sci. USA 2013, 110, 18144-18149. [CrossRef]

60. Li, Y.; Li, Y.; Zhang, H.; Chen, Y. MicroRNA mediated positive feedback loop and optimized bistable switch in a cancer network involving miR-17-92. PLoS ONE 2011, 6, e26302. [CrossRef]

61. Huang, B.; Jolly, M.K.; Lu, M.; Tsarfaty, I.; Ben-Jacob, E.; Jose'N, O. Modeling the transitions between collective and solitary migration phenotypes in cancer metastasis. Sci. Rep. 2015, 5, 17379. [CrossRef]

62. Zhang, Z.; Zha, Y.; Hu, W.; Huang, Z.; Gao, Z.; Zang, Y.; Chen, J.; Dong, L.; Zhang, J. The autoregulatory feedback loop of microRNA-21/programmed cell death protein 4/activation protein-1 (MiR-21/PDCD4/AP-1) as a driving force for hepatic fibrosis development. J. Biol. Chem. 2013, 288, 37082-37093. [CrossRef]

63. Goodfellow, M.; Phillips, N.E.; Manning, C.; Galla, T.; Papalopulu, N. microRNA input into a neural ultradian oscillator controls emergence and timing of alternative cell states. Nat. Commun. 2014, 5, 3399. [CrossRef] [PubMed]

64. Zhou, P.; Cai, S.; Liu, Z.; Wang, R. Mechanisms generating bistability and oscillations in microRNA mediated motifs. Phys. Rev. E 2012, 85, 041916. [CrossRef] [PubMed]

65. Xue, X.; Xia, W.; Wenzhong, H. A modeled dynamic regulatory network of NF- $k$ B and IL-6 mediated by miRNA. Biosystems 2013, 114, 214-218. [CrossRef] [PubMed]

66. Boldin, M.P.; Baltimore, D. MicroRNAs, new effectors and regulators of NF- $\kappa$ B. Immunol. Rev. 2012, 246, 205-220. [CrossRef] [PubMed]

67. Kobayashi, T.; Kageyama, R. Hes1 regulates embryonic stem cell differentiation by suppressing Notch signaling. Genes Cells 2010, 15, 689-698. [CrossRef]

68. Moore, R.; Ooi, H.K.; Kang, T.; Bleris, L.; Ma, L. MiR-192 mediated positive feedback loop controls the robustness of stress-induced p53 oscillations in breast cancer cells. PLoS Comput. Biol. 2015, 11, e1004653. [CrossRef]

69. Chen, R.; D'Alessandro, M.; Lee, C. miRNAs are required for generating a time delay critical for the circadian oscillator. Curr. Biol. 2013, 23, 1959-1968. [CrossRef]

70. Xue, Y.; Zhang, Y. Emerging roles for microRNA in the regulation of Drosophila circadian clock. BMC Neurosci. 2018, 19, 1. [CrossRef]

71. Krol, J.; Busskamp, V.; Markiewicz, I.; Stadler, M.B.; Ribi, S.; Richter, J.; Duebel, J.; Bicker, S.; Fehling, H.J.; Schübeler, D.; et al. Characterizing light-regulated retinal microRNAs reveals rapid turnover as a common property of neuronal microRNAs. Cell 2010, 141, 618-631. [CrossRef]

72. Wang, X.; Tian, G.; Li, Z.; Zheng, L. The crosstalk between miRNA and mammalian circadian clock. Curr. Med. Chem. 2015, 22, 1582-1588. [CrossRef] 
73. Gao, Q.; Zhou, L.; Yang, S.Y.; Cao, J.M. A novel role of microRNA 17-5p in the modulation of circadian rhythm. Sci. Rep. 2016, 6, 30070. [CrossRef] [PubMed]

74. Inukai, S.; Pincus, Z.; De Lencastre, A.; Slack, F.J. A microRNA feedback loop regulates global microRNA abundance during ageing. RNA 2018, 24, 159-172. [CrossRef] [PubMed]

75. Inukai, S.; de Lencastre, A.; Turner, M.; Slack, F. Novel microRNAs differentially expressed during ageing in the mouse brain. PLOS ONE 2012, 7, e40028. [CrossRef] [PubMed]

76. Kim, J.; Inoue, K.; Ishii, J.; Vanti, W.B.; Voronov, S.V.; Murchison, E.; Hannon, G.; Abeliovich, A. A MicroRNA feedback circuit in midbrain dopamine neurons. Science 2007, 317, 1220-1224. [CrossRef]

77. Martinez, N.J.; Ow, M.C.; Barrasa, M.I.; Hammell, M.; Sequerra, R.; Doucette-Stamm, L.; Roth, F.P.; Ambros, V.R.; Walhout, A.J. A C. elegans genome-scale microRNA network contains composite feedback motifs with high flux capacity. Genes Dev. 2008, 22, 2535-2549. [CrossRef]

78. Zhao, H.; Kalota, A.; Jin, S.; Gewirtz, A.M. The c-myb proto-oncogene and microRNA-15a comprise an active autoregulatory feedback loop in human hematopoietic cells. Blood 2009, 113, 505-516. [CrossRef]

79. Pulikkan, J.A.; Dengler, V.; Peramangalam, P.S.; Zada, A.A.P.; Müller-Tidow, C.; Bohlander, S.K.; Tenen, D.G.; Behre, G. Cell-cycle regulator E2F1 and microRNA-223 comprise an autoregulatory negative feedback loop in acute myeloid leukemia. Blood 2010, 115, 1768-1778. [CrossRef]

80. Kefas, B.; Comeau, L.; Floyd, D.H.; Seleverstov, O.; Godlewski, J.; Schmittgen, T.; Jiang, J.; Li, Y.; Chiocca, E.A.; Lee, J.; et al. The neuronal microRNA miR-326 acts in a feedback loop with notch and has therapeutic potential against brain tumours. J. Neurosci. 2009, 29, 15161-15168. [CrossRef]

81. Daneshvar, K.; Nath, S.; Khan, A.; Shover, W.; Richardson, C.; Goodliffe, J.M. MicroRNA miR-308 regulates dMyc through a negative feedback loop in Drosophila. Biol. Open 2013, 2, 1-9. [CrossRef]

82. Mathew, R.S.; Tatarakis, A.; Rudenko, A.; Johnson-Venkatesh, E.M.; Yang, Y.J.; Murphy, E.A.; Todd, T.P.; Schepers, S.T.; Siuti, N.; Martorell, A.J.; et al. A microRNA negative feedback loop downregulates vesicle transport and inhibits fear memory. Elife 2016, 5, e22467. [CrossRef]

83. Zuo, H.; Yuan, J.; Chen, Y.; Li, S.; Su, Z.; Wei, E.; Li, C.; Weng, S.; Xu, X.; He, J. A microRNA mediated positive feedback regulatory loop of the NF- $\kappa \mathrm{B}$ pathway in Litopenaeus vannamei. J. Immunol. 2016, 196, 3842-3853. [CrossRef] [PubMed]

84. Gao, K.; Yin, J.; Dong, J. Deregulated WWOX is involved in a negative feedback loop with microRNA-214-3p in osteosarcoma. Int. J. Mol. Med. 2016, 38, 1850-1856. [CrossRef] [PubMed]

85. Griss, K.; Bertrams, W.; Sittka-Stark, A.; Seidel, K.; Stielow, C.; Hippenstiel, S.; Suttorp, N.; Eberhardt, M.; Wilhelm, J.; Vera, J.; et al. MicroRNAs constitute a negative feedback loop in Streptococcus pneumoniae-induced macrophage activation. J. Infect. Dis. 2016, 214, 288-299. [CrossRef] [PubMed]

86. Ru, P.; Guo, D. microRNA-29 mediates a novel negative feedback loop to regulate SCAP/SREBP-1 and lipid metabolism. RNA Dis. 2017, 4. [CrossRef]

87. Liep, J.; Rabien, A.; Jung, K. Feedback networks between microRNAs and epigenetic modifications in urological tumours. Epigenetics 2012, 7, 315-325. [CrossRef]

88. Siciliano, V.; Garzilli, I.; Fracassi, C.; Criscuolo, S.; Ventre, S.; Di Bernardo, D. miRNAs confer phenotypic robustness to gene networks by suppressing biological noise. Nat. Commun. 2013, 4, 2364. [CrossRef]

89. Zhao, Y.; Srivastava, D. A developmental view of microRNA function. Trends Biochem. Sci. 2007, 32, $189-197$. [CrossRef]

90. van Boxtel, A.; Chesebro, J.; Heliot, C.; Ramel, M.; Stone, R.; Hill, C. A Temporal Window for Signal Activation Dictates the Dimensions of a Nodal Signaling Domain. Dev. Cell 2015, 35, 175-85. [CrossRef]

91. Cassidy, J.J.; Jha, A.R.; Posadas, D.M.; Giri, R.; Venken, K.J.; Ji, J.; Jiang, H.; Bellen, H.J.; White, K.P.; Carthew, R.W. miR-9a minimizes the phenotypic impact of genomic diversity by buffering a transcription factor. Cell 2013, 155, 1556-1567. [CrossRef]

92. Li, Y.; Wang, F.; Lee, J.A.; Gao, F.B. MicroRNA-9a ensures the precise specification of sensory organ precursors in Drosophila. Genes Dev. 2006, 20, 2793-2805. [CrossRef]

93. Chang, S.; Johnston, R.J., Jr.; Frøkjær-Jensen, C.; Lockery, S.; Hobert, O. MicroRNAs act sequentially and asymmetrically to control chemosensory laterality in the nematode. Nature 2004, 430, 785-789. [CrossRef] [PubMed]

94. Tian, W.; Du, Y.; Ma, Y.; Gu, L.; Zhou, J.; Deng, D. MALAT1-miR663a negative feedback loop in colon cancer cell functions through direct miRNA-lncRNA binding. Cell Death Dis. 2018, 9, 857. [CrossRef] [PubMed] 
95. Melling, G.E.; Flannery, S.E.; Abidin, S.A.; Clemmens, H.; Prajapati, P.; Hinsley, E.E.; Hunt, S.; Catto, J.W.; Coletta, R.D.; Mellone, M.; et al. A miRNA-145/TGF- $\beta 1$ negative feedback loop regulates the cancer associated fibroblast phenotype. Carcinogenesis 2018, 39, 798-807. [CrossRef] [PubMed]

96. Zhang, J.; Ma, L. MicroRNA control of epithelial-mesenchymal transition and metastasis. Cancer Metastasis Rev. 2012, 31, 653-662. [CrossRef] [PubMed]

97. Tian, X.J.; Zhang, H.; Xing, J. Coupled reversible and irreversible bistable switches underlying TGF $\beta$-induced epithelial to mesenchymal transition. Biophys. J. 2013, 105, 1079-1089. [CrossRef]

98. Lu, M.; Jolly, M.K.; Ben-Jacob, E. Toward decoding the principles of cancer metastasis circuits. Cancer Res. 2014, 74, 4574-4587. [CrossRef]

99. Diepenbruck, M.; Tiede, S.; Saxena, M.; Ivanek, R.; Kalathur, R.K.R.; Lüönd, F.; Meyer-Schaller, N.; Christofori, G. miR-1199-5p and Zeb1 function in a double-negative feedback loop potentially coordinating EMT and tumour metastasis. Nat. Commun. 2017, 8, 1168. [CrossRef]

100. Fang, X.; Yoon, J.G.; Li, L.; Yu, W.; Shao, J.; Hua, D.; Zheng, S.; Hood, L.; Goodlett, D.R.; Foltz, G.; et al. The SOX2 response program in glioblastoma multiform: An integrated ChIP-seq, expression microarray, and microRNA analysis. BMC Genom. 2011, 12, 11. [CrossRef]

101. Kalir, S.; Mangan, S.; Alon, U. A coherent feed-forward loop with a SUM input function prolongs flagella expression in Escherichia coli. Mol. Syst. Biol. 2005, 1, doi:10.1038/msb4100010. [CrossRef]

102. Shalgi, R.; Brosh, R.; Oren, M.; Pilpel, Y.; Rotter, V. Coupling transcriptional and post-transcriptional miRNA regulation in the control of cell fate. Aging 2009, 1, 762-770. [CrossRef]

103. Li, C.J.; Hong, T.; Tung, Y.T.; Yen, Y.P.; Hsu, H.C.; Lu, Y.L.; Chang, M.; Nie, Q.; Chen, J.A. MicroRNA filters Hox temporal transcription noise to confer boundary formation in the spinal cord. Nat. Commun. 2017, 8, 14685. [CrossRef] [PubMed]

104. Kulyté, A.; Kwok, K.H.M.; de Hoon, M.; Carninci, P.; Hayashizaki, Y.; Arner, P.; Arner, E. MicroRNA-27a/b-3p and PPARG regulate SCAMP3 through a feed-forward loop during adipogenesis. Sci. Rep. 2019, 9, 13891. [CrossRef] [PubMed]

105. Kobayashi, K.; Sakurai, K.; Hiramatsu, H.; Inada, K.I.; Shiogama, K.; Nakamura, S.; Suemasa, F.; Kobayashi, K.; Imoto, S.; Haraguchi, T.; et al. The miR-199a/Brm/EGR1 axis is a determinant of anchorage-independent growth in epithelial tumour cell lines. Sci. Rep. 2015, 5, 8428. [CrossRef] [PubMed]

106. Gupta, R.; Fayaz, S.; Singh, S. Identification of gene network motifs for cancer disease diagnosis. In Proceedings of the 2016 IEEE Distributed Computing, VLSI, Electrical Circuits and Robotics (DISCOVER), Mangalore, India, 13-14 August 2016; pp. 179-184.

107. Prabahar, A.; Natarajan, J. MicroRNA mediated network motifs in autoimmune diseases and its crosstalk between genes, functions and pathways. J. Immunol. Methods 2017, 440, 19-26, doi:10.1016/j.jim.2016.10.002. [CrossRef]

108. Shen-Orr, S.S.; Milo, R.; Mangan, S.; Alon, U. Network motifs in the transcriptional regulation network of Escherichia coli. Nat. Genet. 2002, 31, 64-68. [CrossRef]

109. Cohen, E.E.; Rosner, M.R. MicroRNA-regulated feed forward loop network. Cell Cycle 2009, 8, $2477-2478$. [CrossRef]

110. Friard, O.; Re, A.; Taverna, D.; De Bortoli, M.; Corá, D. CircuitsDB: A database of mixed microRNA/transcription factor feed-forward regulatory circuits in human and mouse. BMC Bioinform. 2010, 11, 435. [CrossRef]

111. El Baroudi, M.; Corà, D.; Bosia, C.; Osella, M.; Caselle, M. A curated database of miRNA mediated feed-forward loops involving MYC as master regulator. PLoS ONE 2011, 6, e14742. [CrossRef]

112. Duk, M.A.; Samsonova, M.G.; Samsonov, A.M. Dynamics of miRNA driven feed-forward loop depends upon miRNA action mechanisms. BMC Genom. 2014, 15, S9. [CrossRef]

113. Brosh, R.; Shalgi, R.; Liran, A.; Landan, G.; Korotayev, K.; Nguyen, G.H.; Enerly, E.; Johnsen, H.; Buganim, Y.; Solomon, H.; et al. p53-Repressed miRNAs are involved with E2F in a feed-forward loop promoting proliferation. Mol. Syst. Biol. 2008, 4, 229-229. [CrossRef]

114. Marson, A.; Levine, S.S.; Cole, M.F.; Frampton, G.M.; Brambrink, T.; Johnstone, Connecting microRNA genes to the core transcriptional regulatory circuitry of embryonic stem cells. Cell 2008, 134, 521-533. [CrossRef] [PubMed] 
115. Li, X.; Cassidy, J.J.; Reinke, C.A.; Fischboeck, S.; Carthew, R.W. A MicroRNA Imparts Robustness against Environmental Fluctuation during Development. Cell 2009, 137, 273-282. doi:10.1016/j.cell.2009.01.058. [CrossRef] [PubMed]

116. Cohen, E.E.; Zhu, H.; Lingen, M.W.; Martin, L.E.; Kuo, W.L.; Choi, E.A.; Kocherginsky, M.; Parker, J.S.; Chung, C.H.; Rosner, M.R. A Feed-Forward Loop Involving Protein Kinase C $\alpha$ and MicroRNAs Regulates Tumor Cell Cycle. Cancer Res. 2009, 69, 65-74, doi:10.1158/0008-5472.CAN-08-0377. [CrossRef] [PubMed]

117. Riba, A.; Bosia, C.; El Baroudi, M.; Ollino, L.; Caselle, M. A Combination of Transcriptional and MicroRNA Regulation Improves the Stability of the Relative Concentrations of Target Genes. PLoS Comput. Biol. 2014, 10, e1003490, doi:10.1371/journal.pcbi.1003490. [CrossRef] [PubMed]

118. O'Donnell, K.A.; Wentzel, E.A.; Zeller, K.I.; Dang, C.V.; Mendell, J.T. c-Myc-regulated microRNAs modulate E2F1 expression. Nature 2005, 435, 839-843. [CrossRef] [PubMed]

119. Hilgers, V.; Bushati, N.; Cohen, S.M. Drosophila microRNAs 263a/b confer robustness during development by protecting nascent sense organs from apoptosis. PLoS Biol. 2010, 8, e1000396. [CrossRef]

120. Kim, D.H.; Grün, D.; van Oudenaarden, A. Dampening of expression oscillations by synchronous regulation of a microRNA and its target. Nat. Genet. 2013, 45, 1337-1344. [CrossRef]

121. Farh, K.K.H.; Grimson, A.; Jan, C.; Lewis, B.P.; Johnston, W.K.; Lim, L.P.; Burge, C.B.; Bartel, D.P. The Widespread Impact of Mammalian MicroRNAs on mRNA Repression and Evolution. Science 2005, 310, 1817-1821, doi:10.1126/science.1121158. [CrossRef]

122. Stark, A.; Brennecke, J.; Bushati, N.; Russell, R.B.; Cohen, S.M. Animal MicroRNAs Confer Robustness to Gene Expression and Have a Significant Impact on 3'UTR Evolution. Cell 2005, 123, 1133-1146, doi:10.1016/j.cell.2005.11.023. [CrossRef]

123. Ebert, M.; Sharp, P. Roles for MicroRNAs in Conferring Robustness to Biological Processes. Cell 2012, 149, 515-524, doi:10.1016/j.cell.2012.04.005. [CrossRef]

124. Duk, M.; Samsonov, A.; Samsonova, M. The dynamics of a feed-forward loop depends on the regulator type in its indirect pathway. Biophysics 2015, 60, 163-172. [CrossRef]

125. Duk, M.A.; Rukolaine, S.A. The Ability of Feed-Forward Regulatory Loops to Adapt: Dependence on Model Parameters and Conditions of Absolute Adaptation. Biophysics 2018, 63, 837-846, doi:10.1134/S0006350918060088. [CrossRef]

126. Kumar, R.M.; Cahan, P.; Shalek, A.K.; Satija, R.; Jay DaleyKeyser, A.; Li, H.; Zhang, J.; Pardee, K.; Gennert, D.; Trombetta, J.J.; et al. Deconstructing transcriptional heterogeneity in pluripotent stem cells. Nature 2014, 516, 56-61. [CrossRef] [PubMed]

127. Klein, A.M.; Mazutis, L.; Akartuna, I.; Tallapragada, N.; Veres, A.; Li, V.; Peshkin, L.; Weitz, D.A.; Kirschner, M.W. Droplet barcoding for single-cell transcriptomics applied to embryonic stem cells. Cell 2015, 161, 1187-1201. [CrossRef] [PubMed]

128. Wu, C.I.; Shen, Y.; Tang, T. Evolution under canalization and the dual roles of microRNAs: A hypothesis. Genome Res. 2009, 19, 734-743. [CrossRef] [PubMed]

129. Bao, H.; Kommadath, A.; Plastow, G.S.; Tuggle, C.K.; Stothard, P. MicroRNA buffering and altered variance of gene expression in response to Salmonella infection. PLoS ONE 2014, 9, e94352. [CrossRef] [PubMed]

130. He, P.; Billy, K.J.; Ma, H.; Jia, Y.; Yang, L. The dynamical roles of miR-17-92 on the E2F related network during the G1/S transition. Nonlinear Dyn. 2019, 95, 259-271. [CrossRef]

131. Hornstein, E.; Shomron, N. Canalization of development by microRNAs. Nat. Genet. 2006, 38, S20-S24. [CrossRef]

132. Kadelka, C.; Murrugarra, D.; Laubenbacher, R. Stabilizing Gene Regulatory Networks through Feedforward Loops. Chaos 2013, 23, 025107, doi:10.1063/1.4808248. [CrossRef]

133. Hsieh, W.T.; Tzeng, K.R.; Ciou, J.S.; Tsai, J.; Kurubanjerdjit, N.; Huang, C.H.; Ng, K.L. Transcription factor and microRNA-regulated network motifs for cancer and signal transduction networks. BMC Syst. Biol. 2015, 9, 55, doi:10.1186/1752-0509-9-S1-S5. [CrossRef]

134. Zhao, Q.; Liu, H.; Yao, C.; Shuai, J.; Sun, X. Effect of Dynamic Interaction between microRNA and Transcription Factor on Gene Expression. BioMed Res. Int. 2016, 2016, 1-10, doi:10.1155/2016/2676282. [CrossRef] [PubMed]

135. Carignano, A.; Mukherjee, S.; Singh, A.; Seelig, G. Extrinsic Noise Suppression in Micro RNA mediated Incoherent Feedforward Loops. bioRxiv 2018, doi:10.1101/422394. [CrossRef] 
136. Bokes, P.; Hojcka, M.; Singh, A. Buffering gene expression noise by microRNA based feedforward regulation. In International Conference on Computational Methods in Systems Biology; Springer: Cham, Switzerland, 2018; pp. 129-145.

137. Grigolon, S.; Patti, F.D.; Martino, A.D.; Marinari, E. Noise processing by microRNA mediated circuits: The Incoherent Feed-Forward Loop, revisited. Heliyon 2016, 2, e00095, doi:10.1016/j.heliyon.2016.e00095. [CrossRef] [PubMed]

138. Xu, F.-D.; Liu, Z.-R.; Zhang, Z.-Y.; Shen, J.-W. Robust and Adaptive MicroRNA-Mediated Incoherent Feedforward Motifs. Chin. Phys. Lett. 2009, 26, 028701, doi:10.1088/0256-307x/26/2/028701. [CrossRef]

139. Hong, J.; Brandt, N.; Abdul-Rahman, F.; Yang, A.; Hughes, T.; Gresham, D. An incoherent feedforward loop facilitates adaptive tuning of gene expression. eLife 2018, 7, e32323. [CrossRef]

140. Bleris, L.; Xie, Z.; Glass, D.; Adadey, A.; Sontag, E.; Benenson, Y. Synthetic incoherent feedforward circuits show adaptation to the amount of their genetic template. Mol. Syst. Biol. 2011, 7, 519. [CrossRef]

141. Kittelmann, S.; McGregor, A.P. Modulation and evolution of animal development through microRNA regulation of gene expression. Genes 2019, 10, 321. [CrossRef]

142. Adler, M.; Szekely, P.; Mayo, A.; Alon, U. Optimal Regulatory Circuit Topologies for Fold-Change Detection. Cell Syst. 2017, 4, 171-181.e8, doi:10.1016/j.cels.2016.12.009. [CrossRef]

143. Goentoro, L.; Shoval, O.; Kirschner, M.W.; Alon, U. The incoherent feedforward loop can provide fold-change detection in gene regulation. Mol. Cell 2009, 36, 894-899. [CrossRef]

144. Schmitt, D.; Tan, M. The enemy within: Regulation of host genes by intronic microRNAs. Chemotherapy 2014, 3, e126.

145. Lutter, D.; Marr, C.; Krumsiek, J.; Lang, E.W.; Theis, F.J. Intronic microRNAs support their host genes by mediating synergistic and antagonistic regulatory effects. BMC Genom. 2010, 11, 224. [CrossRef] [PubMed]

146. Budach, S.; Heinig, M.; Marsico, A. Principles of microRNA regulation revealed through modeling microrna expression quantitative trait loci. Genetics 2016, 203, 1629-1640. [CrossRef] [PubMed]

147. Strovas, T.J.; Rosenberg, A.B.; Kuypers, B.E.; Muscat, R.A.; Seelig, G. MicroRNA-based single-gene circuits buffer protein synthesis rates against perturbations. ACS Synth. Biol. 2014, 3, 324-331. [CrossRef] [PubMed]

148. Han, J.; Denli, A.M.; Gage, F.H. The enemy within: Intronic miR-26b represses its host gene, ctdsp2, to regulate neurogenesis. Genes Dev. 2012, 26, 6-10. [CrossRef] [PubMed]

149. Dill, H.; Linder, B.; Fehr, A.; Fischer, U. Intronic miR-26b controls neuronal differentiation by repressing its host transcript, ctdsp2. Genes Dev. 2012, 26, 25-30. [CrossRef]

150. Kos, A.; Loohuis, N.F.O.; Wieczorek, M.L.; Glennon, J.C.; Martens, G.J.; Kolk, S.M.; Aschrafi, A. A potential regulatory role for intronic microRNA-338-3p for its host gene encoding apoptosis associated tyrosine kinase. PLOS ONE 2012, 7, e31022. [CrossRef]

151. Liu, M.; Roth, A.; Yu, M.; Morris, R.; Bersani, F.; Rivera, M.N.; Lu, J.; Shioda, T.; Vasudevan, S.; Ramaswamy, S.; et al. The IGF2 intronic miR-483 selectively enhances transcription from IGF2 fetal promoters and enhances tumourigenesis. Genes Dev. 2013, 27, 2543-2548. [CrossRef]

152. Chamorro-Jorganes, A.; Araldi, E.; Rotllan, N.; Cirera-Salinas, D.; Suárez, Y. Autoregulation of glypican-1 by intronic microRNA-149 fine tunes the angiogenic response to FGF2 in human endothelial cells. J. Cell Sci. 2014, 127, 1169-1178. [CrossRef]

153. Hinske, L.C.; Galante, P.A.; Limbeck, E.; Möhnle, P.; Parmigiani, R.B.; Ohno-Machado, L.; Camargo, A.A.; Kreth, S. Alternative polyadenylation allows differential negative feedback of human miRNA miR-579 on its host gene ZFR. PLoS ONE 2015, 10, e0121507. [CrossRef]

154. Qian, J.; Tu, R.; Yuan, L.; Xie, W. Intronic miR-932 targets the coding region of its host gene, Drosophila neuroligin2. Exp. Cell Res. 2016, 344, 183-193. [CrossRef]

155. Chuang, T.D.; Luo, X.; Panda, H.; Chegini, N. miR-93/106b and their host gene, MCM7, are differentially expressed in leiomyomas and functionally target F3 and IL-8. Mol. Endocrinol. 2012, 26, 1028-1042. [CrossRef] [PubMed]

156. Steiman-Shimony, A.; Shtrikman, O.; Margalit, H. Assessing the functional association of intronic miRNAs with their host genes. RNA 2018, 24, 991-1004. [CrossRef] [PubMed]

157. Nowicka, M.; Siebert, H. Designing Distributed Cell Classifier Circuits using a Genetic Algorithm. bioRxiv 2019, 652339 .

158. Lillacci, G.; Benenson, Y.; Khammash, M. Synthetic control systems for high performance gene expression in mammalian cells. Nucleic Acids Res. 2018, 46, 9855-9863. [CrossRef] 
159. Matsuura, S.; Ono, H.; Kawasaki, S.; Kuang, Y.; Fujita, Y.; Saito, H. Synthetic RNA-based logic computation in mammalian cells. Nat. Commun. 2018, 9, 4847. [CrossRef]

160. Leisner, M.; Bleris, L.; Lohmueller, J.; Xie, Z.; Benenson, Y. MicroRNA circuits for transcriptional logic. In Synthetic Gene Networks; Springer: Cham, Switzerland, 2012; pp. 169-186.

161. Ye, H.; Aubel, D.; Fussenegger, M. Synthetic mammalian gene circuits for biomedical applications. Curr. Opin. Chem. Biol. 2013, 17, 910-917. [CrossRef]

162. Xie, Z.; Wroblewska, L.; Prochazka, L.; Weiss, R.; Benenson, Y. Multi-input RNAi-based logic circuit for identification of specific cancer cells. Science 2011, 333, 1307-1311. [CrossRef]

163. Quarton, T.; Ehrhardt, K.; Lee, J.; Kannan, S.; Li, Y.; Ma, L.; Bleris, L. Mapping the operational landscape of microRNAs in synthetic gene circuits. NPJ Syst. Biol. Appl. 2018, 4, 6. [CrossRef]

164. Karagiannis, P.; Fujita, Y.; Saito, H. RNA-based gene circuits for cell regulation. Proc. Jpn. Acad. Ser. B 2016, 92, 412-422. [CrossRef]

165. Bloom, R.J.; Winkler, S.M.; Smolke, C.D. Synthetic feedback control using an RNAi-based gene-regulatory device. J. Biol. Eng. 2015, 9, 5. [CrossRef]

166. Ceroni, F.; Boo, A.; Furini, S.; Gorochowski, T.E.; Borkowski, O.; Ladak, Y.N.; Awan, A.R.; Gilbert, C.; Stan, G.B.; Ellis, T. Burden-driven feedback control of gene expression. Nat. Methods 2018, 15, 387-393. [CrossRef] [PubMed]

167. Enrico Bena, C.; Grob, A.; Isalan, M.; Bosia, C.; Ceroni, F. Commentary: Synthetic addiction extends the productive life time of engineered Escherichia coli populations. Front. Bioeng. Biotechnol. 2018, 6, 77. [CrossRef] [PubMed]

168. Reeves, G.T. The engineering principles of combining a transcriptional incoherent feedforward loop with negative feedback. J. Biol. Eng. 2019, 13, 62. [CrossRef] [PubMed]

169. Becker, K.; Klarner, H.; Nowicka, M.; Siebert, H. Designing miRNA-Based Synthetic Cell Classifier Circuits Using Answer Set Programming. Front. Bioeng. Biotechnol. 2018, 6, 70. [CrossRef]

170. Hirosawa, M.; Fujita, Y.; Parr, C.J.; Hayashi, K.; Kashida, S.; Hotta, A.; Woltjen, K.; Saito, H. Cell-type-specific genome editing with a microRNA-responsive CRISPR-Cas9 switch. Nucleic Acids Res. 2017, 45, e118. [CrossRef]

171. Mohammadi, P.; Beerenwinkel, N.; Benenson, Y. Automated design of synthetic cell classifier circuits using a two-step optimization strategy. Cell Syst. 2017, 4, 207-218. [CrossRef]

172. Endo, K.; Hayashi, K.; Saito, H. Numerical operations in living cells by programmable RNA devices. Sci. Adv. 2019, 5, eaax0835. [CrossRef]

173. Anokye-Danso, F.; Snitow, M.; Morrisey, E.E. How microRNAs facilitate reprogramming to pluripotency. J. Cell Sci. 2012, 125, 4179-4787. [CrossRef]

174. Healy, C.; Deans, T. Genetic circuits to engineer tissues with alternative functions. J. Biol. Eng. 2019, 13, 39. [CrossRef]

175. Markopoulos, G.S.; Roupakia, E.; Tokamani, M.; Alabasi, G.; Sandaltzopoulos, R.; Marcu, K.B.; Kolettas, E. Roles of NF- $\kappa$ B signaling in the regulation of miRNAs impacting on inflammation in cancer. Biomedicines 2018, 6, 40. [CrossRef]

176. Rokavec, M.; Öner, M.G.; Hermeking, H. lnflammation-induced epigenetic switches in cancer. Cell. Mol. Life Sci. 2016, 73, 23-39. [CrossRef] [PubMed]

177. Markopoulos, G.S.; Roupakia, E.; Tokamani, M.; Chavdoula, E.; Hatziapostolou, M.; Polytarchou, C.; Marcu, K.B.; Papavassiliou, A.G.; Sandaltzopoulos, R.; Kolettas, E. A step-by-step microRNA guide to cancer development and metastasis. Cell. Oncol. 2017, 40, 303-339. [CrossRef] [PubMed]

178. Hermeking, H. MicroRNAs in the p53 network: Micromanagement of tumour suppression. Nat. Rev. Cancer 2012, 12, 613. [CrossRef] [PubMed]

179. Rokavec, M.; Li, H.; Jiang, L.; Hermeking, H. The p53/miR-34 axis in development and disease. J. Mol. Cell Biol. 2014, 6, 214-230. [CrossRef]

180. Yamakuchi, M.; Lowenstein, C.J. MiR-34, SIRT1, and p53: The feedback loop. Cell Cycle 2009, 8, 712-715. [CrossRef] [PubMed]

181. Markopoulos, G.S.; Roupakia, E.; Marcu, K.B.; Kolettas, E. Epigenetic Regulation of Inflammatory Cytokine-Induced Epithelial-To-Mesenchymal Cell Transition and Cancer Stem Cell Generation. Cells 2019, 8, 1143. [CrossRef] [PubMed] 
182. Cesana, M.; Cacchiarelli, D.; Legnini, I.; Santini, T.; Sthandier, O.; Chinappi, M.; Tramontano, A.; Bozzoni, I. A long noncoding RNA controls muscle differentiation by functioning as a competing endogenous RNA. Cell 2011, 147, 358-369. [CrossRef]

183. Cheng, E.c.; Lin, H. Repressing the repressor: A lincRNA as a MicroRNA sponge in embryonic stem cell self-renewal. Dev. Cell 2013, 25, 1-2. [CrossRef]

184. Martirosyan, A.; De Martino, A.; Pagnani, A.; Marinari, E. ceRNA crosstalk stabilizes protein expression and affects the correlation pattern of interacting proteins. Sci. Rep. 2017, 7, 43673. [CrossRef]

185. Del Giudice, M.; Bosia, C.; Grigolon, S.; Bo, S. Stochastic sequestration dynamics: A minimal model with extrinsic noise for bimodal distributions and competitors correlation. Sci. Rep. 2018, 8, 10387. [CrossRef]

186. Martirosyan, A.; Del Giudice, M.; Enrico Bena, C.; Pagnani, A.; Bosia, C.; De Martino, A. Kinetic Modelling of Competition and Depletion of Shared miRNAs by Competing Endogenous RNAs. In Computational Biology of Non-Coding RNA: Methods and Protocols; Springer: New York, NY, USA, 2019; pp. 367-409.

187. Yuan, Y.; Liu, B.; Xie, P.; Zhang, M.Q.; Li, Y.; Xie, Z.; Wang, X. Model-guided quantitative analysis of microRNA mediated regulation on competing endogenous RNAs using a synthetic gene circuit. Proc. Natl. Acad. Sci. USA 2015, 112, 3158-3163. [CrossRef] [PubMed]

188. Bosia, C.; Sgrò, F.; Conti, L.; Baldassi, C.; Brusa, D.; Cavallo, F.; Cunto, F.D.; Turco, E.; Pagnani, A.; Zecchina, R. RNAs competing for microRNAs mutually influence their fluctuations in a highly non-linear microRNA-dependent manner in single cells. Genome Biol. 2017, 18, 37, doi:10.1186/s13059-017-1162-x. [CrossRef] [PubMed]

189. Rzepiela, A.J.; Ghosh, S.; Breda, J.; Vina-Vilaseca, A.; Syed, A.P.; Gruber, A.J.; Eschbach, K.; Beisel, C.; van Nimwegen, E.; Zavolan, M. Single-cell mRNA profiling reveals the hierarchical response of miRNA targets to miRNA induction. Mol. Syst. Biol. 2018, 14, e8266, doi:10.15252/msb.20188266. [CrossRef] [PubMed]

(C) 2019 by the authors. Licensee MDPI, Basel, Switzerland. This article is an open access article distributed under the terms and conditions of the Creative Commons Attribution (CC BY) license (http:/ / creativecommons.org/licenses/by/4.0/). 